\title{
The pro-inflammatory role of high-mobility group box 1 protein (HMGB-1) in photoreceptors and retinal explants exposed to elevated pressure
}

\author{
Michael RR Böhm ${ }^{1,2,5}$, Maurice Schallenberg ${ }^{1,3,5}$, Katrin Brockhaus ${ }^{1}$, Harutyun Melkonyan ${ }^{1}$ and Solon Thanos ${ }^{1,4}$
}

To determine the role of high-mobility group box 1 protein (HMGB-1) in cellular and tissue models of elevated pressureinduced neurodegeneration, regeneration, and inflammation. Mouse retinal photoreceptor-derived cells (661W) and retinal explants were incubated either under elevated pressure or in the presence of recombinant HMGB-1 (rHMGB-1) to investigate the mechanisms of response of photoreceptors. Immunohistochemistry, western blotting, and the quantitative real-time PCR were used to examine the expression levels of immunological factors (eg, HMGB-1, receptor for advanced glycation end products (RAGE)), Toll-like receptors 2 and 4 (TLR-2, TLR-4), apoptosis-related factors (eg, B-cell lymphoma 2 $(\mathrm{BCl}-2), \mathrm{Bcl}-2$-associated death promoter (Bad)) as well as cytokine expression (eg, tumor necrosis factor alpha (TNF-a), interleukin (IL)-4, IL-6, and vascular endothelial growth factor (VEGF)). The data revealed increased the expression of HMGB-1 and its receptors RAGE, TLR-2, and TLR-4, and TNF- $\alpha$ as well as pro-apoptotic factors (eg, Bad) as well as apoptosis in $661 \mathrm{~W}$ cells exposed to elevated pressure. Co-cultivation of $661 \mathrm{~W}$ cells with rHMGB-1 increased the expression levels of pro-apoptotic Bad and cleaved Caspase-3 resulting in apoptosis. Cytokine array studies revealed an increased release of TNF- $a$, IL-4, IL-6, and VEGF after incubation of 661W cells with rHMGB-1. Upregulation of HMGB-1, TLR-2, and RAGE as well as anti-apoptotic Bcl-2 expression levels was found in the retinal explants exposed to rHMGB-1 or elevated pressure. The results suggest that HMGB-1 promotes an inflammatory response and mediates apoptosis in the pathology of photoreceptors and retinal homeostasis. HMGB-1 may have a key role in ongoing damage of retinal cells under conditions of elevated intraocular pressure.

Laboratory Investigation (2016) 96, 409-427; doi:10.1038/labinvest.2015.156; published online 18 January 2016

Glaucoma is a chronic neurodegenerative disease that is characterized by a progressive loss of retinal ganglion cells (RGCs). ${ }^{1,2}$ Glaucoma-associated degeneration of RGCs involves apoptotic cascades in RGC bodies in the retina and degradation of axons in the optic nerve. Different molecular mechanisms may trigger these processes, making them somewhat compartmentalized. ${ }^{3}$ However, the mechanisms leading to axonal degeneration are not yet fully understood. ${ }^{4}$ Recent studies indicate that glaucomatous tissue damage occurs not only in the inner retina. ${ }^{5}$ Impairment of electrophysiological response together with a decreased number of photoreceptors promotes the evidence of damage in photoreceptors related to elevated pressure in glaucomatous eyes. ${ }^{6-8}$ Swelling of photoreceptors in glaucomatous eyes indicates a primary response as well as additional pathologies owing to elevated pressure and may not reflect retrograde affects owing to dying ganglion cells. Recent studies suppose diminished expression of opsins in ischemic pathologies, eg, owing to choroidal insufficiency related to increased levels of IOP. 9,10

The high-mobility group protein B1 (HMGB-1), which is expressed ubiquitously in mammalian cells, is a highly conserved nuclear protein that participates in DNA replication, recombination, transcription, and repair. ${ }^{1-13}$ The role of HMGB-1 in the central nervous system is barely understood. It has been reported that extracellular HMGB-1 aggravates the tissue damage in ischemic brain infarction models involving neuronal cells. ${ }^{14-16}$ In addition, it has been shown

\footnotetext{
${ }^{1}$ Institute of Experimental Ophthalmology, School of Medicine, Westfalian-Wilhelms-University of Münster, Münster, Germany; ${ }^{2}$ Department of Ophthalmology, St Franziskus Hospital Münster, Münster, Germany; ${ }^{3}$ Department of Ophthalmology, University Hospital Essen, Essen, Germany and ${ }^{4}$ Cluster of Excellence 'Cells in Motion, CiM', Münster, Germany

Correspondence: Dr MRR Böhm, MD, Institute of Experimental Ophthalmology, School of Medicine, Westfalian-Wilhelms-University of Münster, Albert-Schweitzer-Campus 1, D15, Münster 48149, Germany.

E-mail: miboehm@uni-muenster.de

${ }^{5}$ These authors contributed equally to this work.

Received 2 May 2015; revised 26 October 2015; accepted 28 October 2015
} 
that HMGB-1 inhibits glial glutamate transport and increases the extracellular glutamate concentration, which may cause neuronal excitotoxicity. ${ }^{17}$ HMGB-1 interacts with the receptor for advanced glycation end products (RAGE) and members of the family of Toll-like receptors (TLRs), including TLR-2 and TLR-4. Activation of these receptors results in the activation of nuclear factor-kappaB (NF- $\kappa \mathrm{B})$, which influences the production of proinflammatory cytokines. ${ }^{18}$ Within the retina, it has been reported that HMGB-1 expression is observed during diabetic and uveitic retinopathies. ${ }^{19,20}$ We have previously reported that the expression of HMGB-1 in the retina is higher in glaucomatous than in normotensive rats. ${ }^{21}$ However, the exact role of and the mechanisms underlying HMGB-1 activity under high-pressure conditions remain to be elucidated.

The aim of this study was to elucidate the mechanisms associated with HMGB-1 activity in experimental models of glaucoma consisting of photoreceptors and retinal explants cultured under elevated pressure. The main focus was on the photoreceptor response to the release of HMGB-1 caused by elevated pressure, and the HMGB-1 response to immunological and apoptosis-related factors, with the aim of better understanding the mechanisms of photoreceptor responses to elevated pressure. In addition, the responses of HMGB-1exposed $661 \mathrm{~W}$ cells were monitored to explore the associated cytokine- and apoptosis-related reactions, with emphasis on the role of HMGB-1 effects. Finally, the role of HMGB-1 within the retina was confirmed using retinal explants that mimic the complex cellular network within the retinal environment.

\section{MATERIALS AND METHODS Cell Culture}

The retinal photoreceptor-derived cell line $(661 \mathrm{~W})$ was obtained from Dr Agarval. The line was originally provided as RGC-5 but this has been shown to be identical to 661W. ${ }^{22,23}$ The decision to use this cell line in the present study was to study the response of photoreceptors to elevated pressure and based on a recent report that HMGB-1 is regulated in retinal programmed necrosis. ${ }^{24}$ The cells were cultured in Dulbecco's modified Eagle's medium (PAA Laboratories, Pasching, Austria) supplemented with 10\% fetal calf serum (Seromed, Biochrom, Berlin, Germany) and 1\% penicillin/streptomycin $(50 \mu \mathrm{g} / \mathrm{ml}$; Sigma-Aldrich, Hamburg, Germany) in a humidified $\mathrm{CO}_{2}$ incubator at $37^{\circ} \mathrm{C}$. The medium was changed every $2-3$ days. All experiments were performed in triplicate.

\section{Animals and Drugs}

All experiments were conducted in strict accordance with the ARVO Statement for the Use of Animals in Ophthalmic and Vision Research. Male C57BL/6 (WT) mice aged 6-8 weeks and weighing about $12-18 \mathrm{~g}(n=42)$ were housed in a standard animal room under 12-h/12-h light/dark conditions, with food and water provided ad libitum.

\section{Tissue Preparation of Retinal Explants}

Mice were killed and the eyes were removed and sterilized by incubation in betaisodonna. After a circumferential cut, the anterior segment and the sclera were removed and the retinas were flat-mounted with the pigment epithelium layer down on sterile nitrocellulose filters (Sartorius, Göttingen, Germany). The vitreous body was removed with sterile Whatman filters and the retinas were chopped into four pieces centered in the optic disc. With the ganglion cell layer down, these pieces were explanted on petriperm dishes covered with poly-D-lysine (Sigma-Aldrich) and laminin (Roche, Mannheim, Germany). The retina explants were cultured in DMEM high glucose $(6.5 \mathrm{~g} / \mathrm{l})$ supplemented with $10 \%$ FCS and $1 \%$ penicillin/streptomycin for 3 days in humidified atmosphere. All experiments were performed in triplicate.

\section{Organotypic Model of Glaucoma In Vitro}

A high-pressure chamber model was designed for cell and retinal explant cultures, in which cells or explants could be exposed to normotonic or hypertonic conditions. A circular chamber with a diameter of $15 \mathrm{~cm}$ was fabricated from rust-free steel and is able to tolerate constant pressures up to $200 \mathrm{~mm} \mathrm{Hg}$ over several days. An external manometer was used to adjust the pressure. A second manometer continually monitored the intracameral pressure. The lid is screwed to avoid leakage. This system is designed to maintain the desired pressure and to supply the incubator with an atmosphere containing $5 \% \mathrm{CO}_{2}$ through a valve. Cultured cells and explants can thus be exposed to modifiable and stable pressures in the pressure chamber. To guarantee the cell culture conditions, the chamber with the lid open was preincubated in a commercial cell-culture incubator to equilibrate the inner air to $5 \% \quad \mathrm{CO}_{2}$ and $37^{\circ} \mathrm{C}$. The experiments were conducted under the following pressure conditions: 0,20 , and $40 \mathrm{~mm} \mathrm{Hg}$ for $72 \mathrm{~h}$. The group obtained $0 \mathrm{~mm} \mathrm{Hg}$ served as the control group, simulating the normotensive laboratory conditions.

\section{Exposure of $661 \mathrm{~W}$ to Recombinant HMGB-1}

The secondary effects of exposure of $661 \mathrm{~W}$ cells to recombinant HMGB-1 (rHMGB-1) were studied by incubating them with rHMGB-1 (human; Sigma-Aldrich) at increasing concentrations $(100,250,500$, and $1 \mu \mathrm{g} / \mathrm{ml})$ for 24,48 , and $72 \mathrm{~h}$ (data not shown). The used HMGB-1 shows a highly conserved homologous structure ( $\geq 99 \%)$ (http://www.ncbi. nlm.nih.gov/tools/cobalt/) compared with protein sequence in rodents. As shown in a previous study dealing with exposure of different cell lines to rHMGB-1 (eg, SW872 liposarcoma cells), ${ }^{25}$ the main effects of rHMGB-1 on $661 \mathrm{~W}$ are observed with exposure to rHMGB- 1 at a concentration of $1 \mu \mathrm{g} / \mathrm{ml}$ for $24 \mathrm{~h}$. The secondary effects of rHMGB-1 on exposed retinal explants were studied by incubating the explants with $1 \mu \mathrm{g} / \mathrm{ml} \mathrm{rHMGB}-1$ for 24,48 , or $72 \mathrm{~h}(n=4$ animals per group; data not shown). As with $661 \mathrm{~W}$ cells, the 
Table 1 Antibodies for immunohistochemistry and western blotting

\begin{tabular}{|c|c|c|c|}
\hline Antibody & Origin & Dilution & Manufacturer \\
\hline \multicolumn{4}{|c|}{ Primary antibodies } \\
\hline HMGB-1 & Rabbit polyclonal & $1: 100$ & Aviva \\
\hline RAGE & Rabbit polyclonal & $1: 700$ & Abcam \\
\hline TLR-2 & Rabbit polyclonal & $1: 500$ & Sigma-Aldrich \\
\hline TRL-4 & Mouse monoclonal & $1: 100$ & Abcam \\
\hline$\beta$-III Tubulin & Mouse monoclonal & $1: 500$ & Covance \\
\hline Rhodopsin & Mouse monoclonal & $1: 50$ & Milipore \\
\hline GFAP & Mouse monoclonal & $1: 500$ & Sigma-Aldrich \\
\hline |ba-1 & Goat polyclonal & $1: 250$ & Abcam \\
\hline Calretinin & Mouse monoclonal & $1: 250$ & Chemicon \\
\hline \multicolumn{4}{|c|}{ Secondary antibodies } \\
\hline Alexa 488 & Donkey anti-rabbit & $1: 500$ & J. Immunoresearch \\
\hline Alexa 594 & Donkey anti-mouse & $1: 500$ & J. Immunoresearch \\
\hline
\end{tabular}

Western blotting

\begin{tabular}{|c|c|c|c|c|}
\hline Antibody & Origin & $\mathrm{kDa}$ & Dilution & Manufacturer \\
\hline \multicolumn{5}{|l|}{ Primary antibodies } \\
\hline RAGE & Rabbit polyclonal & 45 & $1: 700$ & Abcam \\
\hline Bax & Rabbit polyclonal & 20 & $1: 1000$ & Cell Signaling \\
\hline Bad & Rabbit polyclonal & 23 & $1: 1000$ & Cell Signaling \\
\hline pBad & Mouse monoclonal & 23 & $1: 2000$ & Cell Signaling \\
\hline Cleaved caspase- 3 & Rabbit polyclonal & 19 & $1: 1000$ & Cell Signaling \\
\hline GAPDH & Rabbit polyclonal & 37 & $1: 100000$ & Sigma-Aldrich \\
\hline Beta-Actin & Rabbit polyclonal & 42 & $1: 20000$ & Sigma-Aldrich \\
\hline HRP-conjugated anti-rabbit & Goat & NA & $1: 50000$ & Sigma-Aldrich \\
\hline HRP-conjugated anti-mouse & Goat & NA & $1: 50000$ & Sigma-Aldrich \\
\hline
\end{tabular}

Bad, Bcl-2-associated death promoter; Bax, bcl-2-associated X-protein; Bcl-2, B-cell lymphoma 2; GAPDH, glyceraldehyde 3-phosphate dehydrogenase; GFAP, glial fibrillary acidic protein; HMGB-1, high-mobility group B1 protein; Iba-1, ionized calcium-binding adaptor molecule 1; NA, not applicable; $p$ Bad, phosphorylated Bad; RAGE, receptor for advanced glycation end products; TLR, Toll-like receptor.

main effects on retinal explants were observed after the addition of $1 \mu \mathrm{g} / \mathrm{ml} \mathrm{rHMGB}-1$ for $24 \mathrm{~h}$.

\section{Immunohistochemistry (IHC)}

Cells were grown on cover slips, fixed in $4 \%$ paraformaldehyde $10 \mathrm{~min}$ at room temperature (RT), and then washed in
PBS. The cultures were incubated with blocking solution containing $10 \%$ FCS containing $0.25 \%$ TritonX-100 for $2 \mathrm{~h}$ at RT and then with primary antibodies diluted in $10 \%$ FCS overnight at $4{ }^{\circ} \mathrm{C}$. After washing with PBS, the cells were incubated with secondary antibodies diluted in 10\% FCS $(1 \mathrm{~h}$ for RT), washed in PBS, and then cover-slipped with antifade 
mounting medium (Mowiol, Hoechst, Frankfurt, Germany) containing bis-Benzimide (Hoechst 33342) to stain cell nuclei. The slides were viewed with the appropriate filter on a microscope equipped with epifluorescence (Imager 2, Carl Zeiss, Jena, Germany) and appropriate software (ZEN 2012, Carl Zeiss) using plan achromat $\times 63 / 1.4$ oil. Quantification of mean optical density was accomplished by using the Image-J software (http://rsb.info.nih.gov/ij/index.html). The nuclear region was defined as the central region 10 pixels inset from the nuclear/cytoplasm boundary. The cytoplasmic region was defined as a disc beginning at the nuclear/ cytoplasmic boundary and extending 10 pixels into the cytoplasm. The statistic evaluated was the ratio of the average cytoplasmic region intensity to the average nuclear region intensity for each cell in relation to the cytoplasmic/nuclear fluorescent intensity $(C: N)$ ratio of control. $C: N$ ratios $>1$ implies increased cytoplasmic retention, whereas $C: N$ ratios $<1$ indicates increased nuclear retention. ${ }^{26}$ Negative controls contain the secondary antibody alone. Control and cultured cells were stained simultaneously to avoid variations in IHC staining. The antibodies used are listed in Table 1.

\section{Western Blotting (WB) Analysis}

WB analysis was used to probe for the expression levels of immunological factors HMGB-1 (Aviva/Acris, Herford, Germany) and RAGE (Abcam, Cambridge, UK) as well as for apoptotic-related factors B-cell lymphoma 2 (Bcl-2) (Sigma-Aldrich), bcl-2-associated X-protein (Bax) (Merck/ Calbiochem, Schwalbach, Germany), Bcl-2-associated death promoter (Bad) (Cell Signaling, Leiden, The Netherlands), and phosphorylated Bad ( $p$ Bad) (Cell Signaling) in 661W cells exposed to elevated pressure. The antibodies for TLR-2 (Sigma-Aldrich) and TLR-4 (Abcam) were not suitable for WB and were only used for IHC.

For WB analysis, $2.5 \times 10^{5} 661 \mathrm{~W}$ cells were cultured in six-well plates, as described above. Thereafter, the cultured cells were harvested by trypsinization and washed twice with PBS. To distinguish the localization of HMGB-1 and RAGE in the cytoplasm and/or the nucleus, cells were resuspended in hypotonic buffer $(20 \mathrm{mM}$ Tris pH7,4; $10 \mathrm{mM} \mathrm{NaCl} ; 3 \mathrm{mM}$ $\mathrm{MgCl}_{2}$ ) supplemented with protease and phosphatase inhibitors (Roche; Sigma-Aldrich) and incubated on ice for $15 \mathrm{~min}$. After centrifugation $\left(10 \mathrm{~min}, 3000 \mathrm{~g},+4^{\circ} \mathrm{C}\right)$ the supernatant was saved as cytoplasmic extract (cytoplasm). The remaining pellet was resuspended in nuclear cell extraction buffer (50 mM Tris pH 7.4; $150 \mathrm{mM} \mathrm{NaCl;} 2 \mathrm{mM}$ EDTA; 0.5\% sodium deoxycholate; $1 \%$ Triton X-100; $10 \%$ glycerin; $1 \mathrm{mM}$ DTT; $0.25 \%$ sodium dodecylsulfate (SDS)) supplemented with protease and phosphatase inhibitors and kept on ice for $30 \mathrm{~min}$. After centrifugation $\left(30 \mathrm{~min}, 15800 \mathrm{~g},+4^{\circ} \mathrm{C}\right)$, the supernatant was saved as nuclear-membrane extract. To study the expression of apoptosis-related factors, cells were lysed in RIPA buffer (containing $0.25 \%$ SDS) with additional protease inhibitor cocktail (Roche) and $1 \mathrm{mM}$ phenylmethylsulfonyl fluoride (Sigma-Aldrich), followed by further trituration and ultrasound treatment. The protein concentrations were determined using Bradford reagents (Bio-Rad, München, Germany). The samples were then transferred to SDS sample buffer containing $130 \mathrm{mM}$ Tris-HCl (Carl Roth, Karslruhe, Germany), 10\% w/v SDS, 10\% mercaptophenol, 20\% glycerol, and $0.06 \% \mathrm{w} / \mathrm{v}$ bromophenol blue (all Sigma-Aldrich). Fifty micrograms of protein from each sample were fractionated on $12 \%$ and $14 \%$ SDS-polyacrylamide gels (depending on the molecular weight of the target protein) with a protein marker (Bio-Rad, Hercules, CA, USA). After electrophoresis, the proteins were transferred onto a nitrocellulose membrane (Whatman, GE Healthcare Europe, Freiburg, Germany). The blots were incubated in blocking solution containing $5 \%$ fat-free dried milk (Carl Roth) for $1 \mathrm{~h}$, followed by incubation overnight at $4{ }^{\circ} \mathrm{C}$ with a primary antibody, as listed in Table 1. As a control antibody, we used calnexin (dilution 1:10 000), beta-Actin (dilution 1:20 000), and glyceraldehyde 3-phosphate dehydrogenase (GAPDH; dilution 1:100 000). The membrane was then incubated with a horseradishperoxidase-conjugated secondary antibody (Sigma-Aldrich) in blocking solution for $1 \mathrm{~h}$ at RT. Antibodies were detected by enhanced chemiluminescence (Amersham, Rockville, MD, USA), and the relative densities of the protein spots were analyzed using Alpha Ease (Alpha-Ease FC software 4.0, Alpha Innotech, Biozym Scientific, Vienna, Austria). The protein density of a fixed area was determined for each spot after subtracting the specific background density in the surrounding region. The spot density was correlated and corrected against the relative density of the particular application control. The spot density of the samples from the control group was defined as the respective reference values, and the relative values of other groups were calculated. Means and s.ds. of the relative relationships of the proteins were obtained for gels of three individual samples, each run three times for each individual group. The primary and secondary antibodies used are listed in Table 1.

\section{Quantitative Real-Time PCR (qRT-PCR)}

RNA isolation was performed with the Gene Elute Mammalian Total RNA Miniprep Kit (Sigma Aldrich) according to the protocols provided by the manufacturer. Quantification was achieved using an UV/visual spectral photometer (NanoDrop ND-1 000, Peqlab, Erlangen, Germany). cDNA was synthesized from $1 \mu \mathrm{g}$ of total RNA using the High Capacity cDNA Reverse Transcription Kit from Applied Biosystems (ABI, Foster City, CA, USA). The following qRT-PCR primer pairs designed for SYBR-Green-based qRT-PCR were used for the analysis:

HMGB-1 (NM_010439.3)—forward， 5'-TGCGTCTGGC TCCCGCTCTC-3'; reverse, 5'-AGAGTCGCCCAGTGCCCG $\mathrm{T}-3^{\prime}$.

TLR-2 (NM_011905)—forward, 5'-CATCACCGGTCAGA AAACAA-3'; reverse, 5'-ACCAAGATCCAGAAGAGCCA-3'. 


\section{$661 \mathrm{~W}$ cells under elevated pressure}

a

HMGB-1

Calnexin

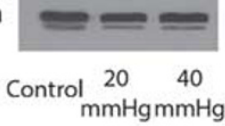

Cytoplasm

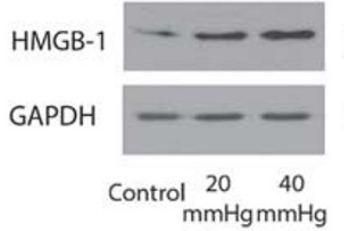

b

Western blotting of HMGB-1

[25kDa]

$[90 \mathrm{kDa}]$

$[25 \mathrm{kDa}]$

$[37 \mathrm{kDa}]$
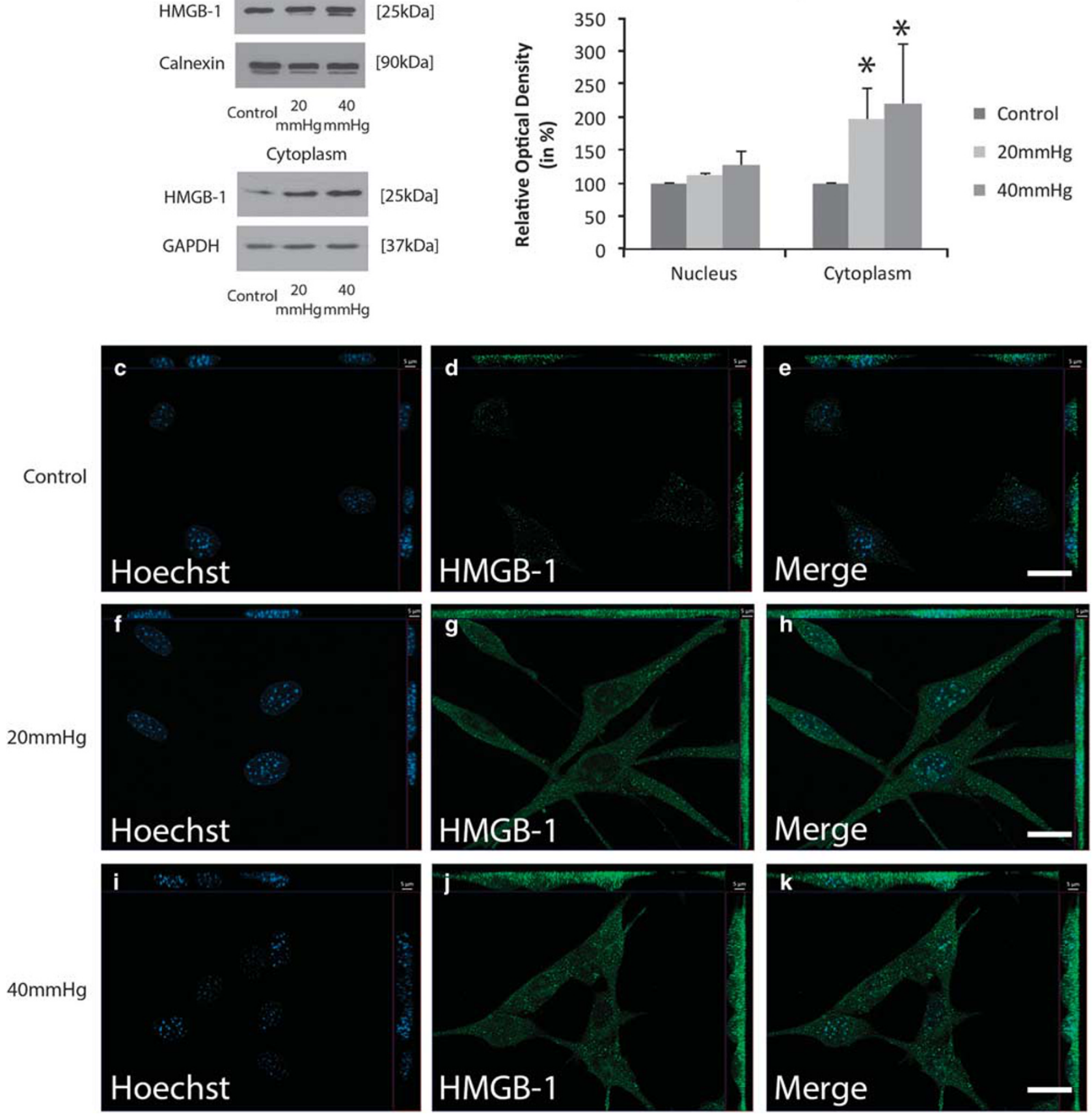

Figure 1 Protein and mRNA expression of HMGB-1 by 661W cells under elevated pressure. The expression of HMGB-1 was examined by western blotting analysis. (a) Nucleus/membrane and cytoplasmic lysates of $661 \mathrm{~W}$ cells exposed to elevated pressure were prepared and tested for HMGB-1 (25 kilo Dalton $(\mathrm{kDa}))$. Calnexin $(90 \mathrm{kDa})$ and glyceraldehyde 3-phosphate dehydrogenase (GAPDH, $37 \mathrm{kDa})$ expression verified the amount of protein loaded per lane. (b) Corresponding densitometric analyses of the western blotting results for HMGB-1 with exposure to elevated pressure in relation to unaffected control $(0 \mathrm{~mm} \mathrm{Hg}$ ). (c-k) Immunofluorescence microscopy of expression and intercellular localization of HMGB-1 (Alexa 488, green) in 661W cells under elevated pressure. Cell nuclei were stained with bisbenzimide (Hoechst 33342, blue). Apotome images by z-planes stacks at 2.1-2.8- $\mu \mathrm{m}$ intervals: bottom of each panel is an $x y$ en face view of the presented cell layer shown in maximum-intensity projection through the $z$-axis. Top and side of each panel is a cross-section through the z-plane of multiple optical slides. (I) Quantification of the mean fluorescence intensity of HMGB-1 in the cytoplasm versus the nucleus of $661 \mathrm{~W}$ cells under elevated pressure in relation to control. (m) Quantitative real-time PCR (qRT-PCR) results for HMGB-1 mRNA levels in 661W cells exposed to elevated pressure $(20,40 \mathrm{~mm} \mathrm{Hg})$ in relation to unaffected control $(0 \mathrm{~mm} \mathrm{Hg})$. (n) Immunoprecipitation of HMGB-1 in supernatants of $661 \mathrm{~W}$ cells exposed to elevated pressure $(20,40 \mathrm{~mm} \mathrm{Hg}$ ) in relation to unaffected control. (o) Corresponding densitometric analysis of the immunoprecipitation results for HMGB-1 in $661 \mathrm{~W}$ cells exposed to elevated pressure in relation to untreated control. Scale bar, $20 \mu \mathrm{m}$. ${ }^{*}$ Significant differences at $P<0.05$. 

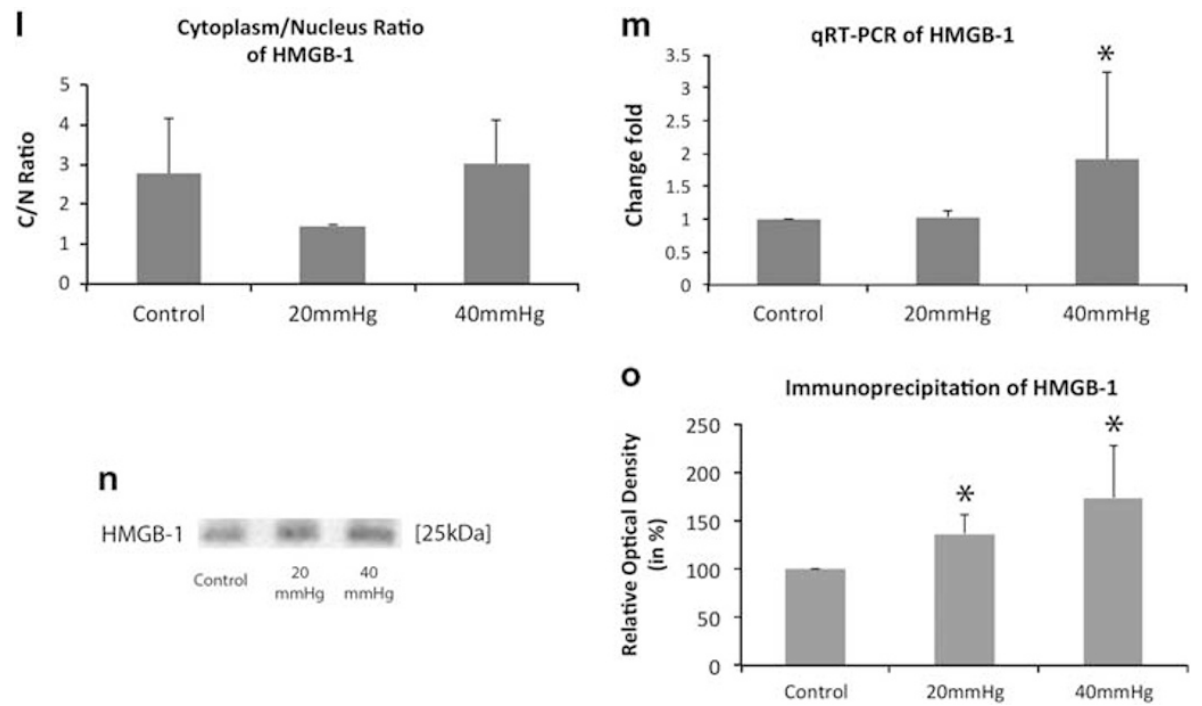

Figure 1 Continued.

TLR-4 (NM_021297)—forward, 5'-TGTTCTTCTCCTGC CTGACA-3'; reverse, 5' ${ }^{\prime}$-TGTCATCAGGGACTTTGCTG-3' .

RAGE (NM_007425.2)—forward, 5'-GCGTGGCTCGAAT CCTCCCC-3'; reverse, 5'-CCCGACACCGGAAAGTCC CC- $3^{\prime}$.

Bcl-2 (NM_009741.3)—forward, 5'-GCCCCAGCATGCG ACCTCTG-3'; reverse, 5'-AGTGATGCAGGCCCCGA CCA-3'.

Bcl-2-associated X-protein (Bax; NM_007527): forward, 5'-GCTGAGCGAGTGTCTCCGGC-3'; reverse, 5'-GGGGAG TCCGTGTCCACGTCA-3'.

The qRT-PCR was performed using the SYBR-Green PCR Kit (ABI) according to the protocols provided by the manufacturer. The relative expression was calculated as $2^{-\Delta \mathrm{Ct}}$ (specific gene) $/ 2^{-\Delta \mathrm{Ct}}$ mean, using the gene encoding glyceraldehyde phosphate dehydrogenase as the endogenous housekeeping control gene. The relative expression (RQ, relative quotient) was calculated and is presented as fold change in relation to the expression level in the control group.

\section{Immunoprecipitation}

After exposure of $661 \mathrm{~W}$ cells and retinal explants under elevated pressure conditions, the culture media were collected and subsequently used for immunoprecipitation experiments to detect secreted extracellular HMGB1. The precipitation of extracellular HMGB1 with specific antibodies (rabbit, Aviva/ Acris) and SureBeads Protein A Magnetic Beads (Bio-Rad, Munich, Germany) was performed according to the suppliers' instructions. To compare the amounts of immunoprecipitated HMGB1 in the different culture media, WB analyses were conducted with the respective precipitates as described before. Probes of $200 \mathrm{ng}$ rHMGB-1 tested in WB analysis served as loading control. Mean and s.ds. of proteins were obtained for gels of three individual samples, each run three times for each individual group.

\section{Cytokine Assay}

Levels of vascular endothelial growth factor (VEGF), tumor necrosis factor alpha (TNF- $\alpha$ ), IL-4, and IL-6 in the supernatants of $661 \mathrm{~W}$ cells or mouse retinal explants treated with $1 \mu \mathrm{g} / \mathrm{ml} \mathrm{rHMGB}-1$ or cultivated under elevated pressure conditions were determined in a cytokine array (Mouse Cytokine Antibody Array CI Kit from RayBiotech, Atlanta, GA, USA) according to the protocol of the manufacturer. Data analysis via densitometry and interpretation were performed according to the protocol of the manufacturer. Mean and s.ds. of cytokines were obtained for arrays of three individual samples.

\section{Cell Viability Assay}

The viability of $661 \mathrm{~W}$ cells exposed to elevated pressure were evaluated using the 3-(4,5-dimethylthiazol-2-yl)-2,5-diphenyl tetrazolium bromide (MTT) assay with the aid of a microplate reader at 570 and $670 \mathrm{~nm}$ (Spectra II, Tecan Group, Männedorf, Switzerland). Cells were seeded in 48-well plates (200 $\mu$ l per well, containing $2 \times 10^{4}$ cells $/ \mathrm{ml}$ ). In all, $20 \mu \mathrm{l}$ MTT (concentration: $5 \mathrm{mg} / \mathrm{ml}$ ) was added to each well for $2 \mathrm{~h}$. Medium was removed and $300 \mu \mathrm{l}$ isopropanol containing $0.04 \mathrm{M} \mathrm{HCl}$ was added to each well to dissolve formazan. Control values were defined as $100 \%$.

\section{TUNEL Assay}

$661 \mathrm{~W}$ cells exposed under elevated pressure conditions, and mouse retinal explants as well as $661 \mathrm{~W}$ cells treated with $1 \mu \mathrm{g} /$ $\mathrm{ml}$ rHMGB-1, were fixed with $4 \%$ PFA for $30 \mathrm{~min}$. After washing with $\mathrm{PBS}, \mathrm{pH} 7.4$, the specimens were incubated with $30 \%$ sucrose overnight at $+4{ }^{\circ} \mathrm{C}$ and subsequently frozen in $\mathrm{N}$-methylbutane cooled in liquid nitrogene. IHC with celltype-specific markers was performed with retinal explants as described above. See Table 1 for antibodies used. Using fixed retinal explants, these were incubated with the first and 
secondary antibodies for 2 days, respectively. For cell-specific labeling, the following antibodies were used: ionized calciumbinding adpater molecule 1 (Iba-1) (rabbit, Wako, Neuss, Germany), glial fibrillary acidic protein (GFAP; rabbit, Sigma-Aldrich), $\beta$-III tubulin (mouse, Covance, Munich, Germany), rhodopsin (mouse, Merck Millipore, Darmstadt, Germany), calbindin, and calretinin (rabbit, Chemicon/Millipore, Darmstadt, Germany). Later, the ApopTag Fluorescein In Situ Apoptosis Detection Kit S7110 from Merck Millipore was used for TUNEL staining according to the manufacturer's protocol. Additional staining of rhodopsin and TUNEL was performed in retinal sections to verify apoptosis in photoreceptors. Retinal explants were treated according to the experimental approach and frozen in tissue tek (Sakura Finetek Europe, Alphen an den Rijn, The Netherlands). Sections were cut with a cryostat (101-m thick, CM 1500; Leica, Bremen, Germany) and mounted onto glass slides. Further IHC staining was performed as described above.

\section{Statistical Analysis}

Mean \pm s.d. values of the obtained data were analyzed with Kolmogorov-Smirnov test to proof Gaussian distribution. The independent samples $t$-test (for a Gaussian distribution) or the Kruskal-Wallis $H$ test (for a non-Gaussian distribution) were used when appropriate. Local $P$-values were corrected for multiple comparisons using the Holm-Bonferroni method. Figures were prepared using the standard image-processing software (Photoshop, Adobe Systems, San Jose, CA, USA), and the overall brightness and contrast were adjusted without retouching. Data are presented as mean $\pm s$. d. values in relation to unaffected control, and the level of statistical significance was set at $P<0.05$.

\section{RESULTS}

\section{HMGB-1 Under Elevated Air Pressure}

First, the expression of HMGB-1 in the nucleus as well as cytoplasm of $661 \mathrm{~W}$ cells under elevated pressure was investigated by $\mathrm{WB}$ analysis. There was a statistically significant increase of HMGB-1 in the cytoplasm $(20 \mathrm{~mm} \mathrm{Hg}$ : $197 \pm 45.8 \%, P<0.05 ; 40 \mathrm{~mm}$ Hg: $220.5 \pm 88.8 \% ; P<0.05)$ compared with control. Within the nucleus, the HMGB-1 expression shows no statistically significant differences (Figures 1a and b). Then the expression patterns and intracellular localization of HMGB-1 was analyzed by IHC. HMGB-1 was mainly located in the cytoplasm of the $661 \mathrm{~W}$ cells. HMGB-1 was also stained in the nucleus under conditions of elevated pressure rather than unaffected control. Moreover, elevated pressure leads to an increase in cell size together with a development of cellular processes. The general staining pattern of HMGB-1 revealed an increase in fluorescence intensity both in the 20 and $40 \mathrm{~mm} \mathrm{Hg}$ group compared with control (Figures 1c-k). The cytoplasm/ nucleus ratio of HMGB-1 revealed no significant changes under elevated pressure compared with control (Figure 11). Then the gene-expression levels of HMGB-1 were examined using qRT-PCR. It remained stable under $20 \mathrm{~mm} \mathrm{Hg}$ (RQ $1.0 \pm 0.08, P=0.29)$ and was higher under elevated pressure (40mHg: RQ $1.92 \pm 1.33, P<0.05)$ compared with control (Figure $1 \mathrm{~m}$ ).

The release of HMGB-1 was explored by immunoprecipitation analysis of the supernatant of $661 \mathrm{~W}$ cells exposed to elevated pressure. There was a statistically significant increase of HMGB-1 release $(20 \mathrm{~mm} \mathrm{Hg:} 136.6 \pm 19.7 \%, P<0.05$; $40 \mathrm{~mm} \mathrm{Hg}: 173.8 \pm 53.4 \%, P<0.05)$ compared with control (Figures $1 \mathrm{n}$ and $\mathrm{o}$ ).

\section{Immunological And Apoptosis-Related Factors Induced By Elevated Pressure}

The response of immunological factors (eg, HMGB-1, TLR-2, TLR-4, and RAGE), viability, apoptosis and its related factors (eg, Bax, Bcl-2, Bad, $p \mathrm{Bad}$ ) in $661 \mathrm{~W}$ cells exposed to elevated air pressure were examined.

\section{Immunological Response Under Elevated Pressure}

The cellular localization and characteristics of TLR-2, TLR-4, and RAGE in $661 \mathrm{~W}$ cells was examined by IHC. Increased staining of the membrane protein TLR-2 has been observed under elevated pressure compared with control. Under elevated pressure, an increase of TLR-2 staining was found rather in complexes of several cells than in individual cells (Figures $2 \mathrm{a}-\mathrm{f}$ ). Comparable changes were revealed by staining of TLR-4 implying an increase of TLR-4 expression under elevated pressure conditions (Figures $2 \mathrm{~g}-1$ ). RAGE was mainly localized in the cytoplasm with rare staining in the nucleus in the control group. Conditions of elevated pressure resulted in less staining of RAGE in the cytoplasm, whereas an increase was observed in the nucleus (Figures $2 \mathrm{~m}-\mathrm{r}$ ).

WB analysis revealed increased RAGE incidence within the nucleus/membrane fraction of pressure-affected $661 \mathrm{~W}$ cells $(20 \mathrm{~mm} \mathrm{Hg}: 126.2 \pm 40.8 \%, P=0.1 ; 40 \mathrm{~mm} \mathrm{Hg}$ : $144.9 \pm 41.8 \%, P<0.05)$, whereas not significant decreased protein levels was found in the cytoplasm $(20 \mathrm{~mm} \mathrm{Hg}$ : $78.7 \pm 25.3 \%, \quad P<0.2 ; \quad 40 \mathrm{~mm} \mathrm{Hg}: \quad 72.9 \pm 20.7 \%, \quad P<0.1)$ compared with control (Figures $2 \mathrm{~s}$ and $\mathrm{t}$ ). The antibody for TLR-2 and TLR-4 was not suitable for WB.

Expression levels of mRNA revealed a slight increase in the mRNA expression levels of TLR-2 under both pressure conditions (20 mm hg: RQ 1.2 $\pm 0.1, P<0.05 ; 40 \mathrm{~mm} \mathrm{Hg}$ : RQ $1.1 \pm 0.1, P<0.05)$. TLR-4 showed an increase in $40 \mathrm{~mm} \mathrm{Hg}$ conditions (RQ $1.8 \pm 0.95, P<0.05$ ) in contrast to stable expression levels under $20 \mathrm{~mm} \mathrm{Hg}$ (RQ $1.0 \pm 0.1, P=0.5$ ), and an increase of RAGE within the $20 \mathrm{~mm} \mathrm{Hg}$ conditions (RQ 1.6 $\pm 0.5, P<0.05$ ). No alterations of mRNA levels of RAGE have been found in the $40 \mathrm{~mm} \mathrm{Hg}$ group (RQ $0.8 \pm 0.5, P=0.2$ ) compared with the control (Figure $2 \mathrm{u}$ ).

\section{Cytokine Release And Elevated Pressure}

The release of cytokines, which are related to immunological reactions in retinal disorders and glaucoma (eg, VEGF, TNF$\alpha$, IL-4, and IL-6), were studied. Dot-blot analysis revealed a 
slight decrease of VEGF $(92.15 \pm 0.4 \%, P<0.05)$ and an increase of TNF- $\alpha(198.1 \pm 20.6 \%, P<0.05)$ in $661 \mathrm{~W}$ cells after exposure to elevated pressure compared with control.
Release of IL-4 $(91.03 \pm 16.7 \%, \quad P=0.5)$ and IL-6 $(78.2 \pm 32.3 \%, P=0.4)$ remained unchanged (Figures 3a and $b)$.

\section{$661 \mathrm{~W}$ cells under elevated pressure}

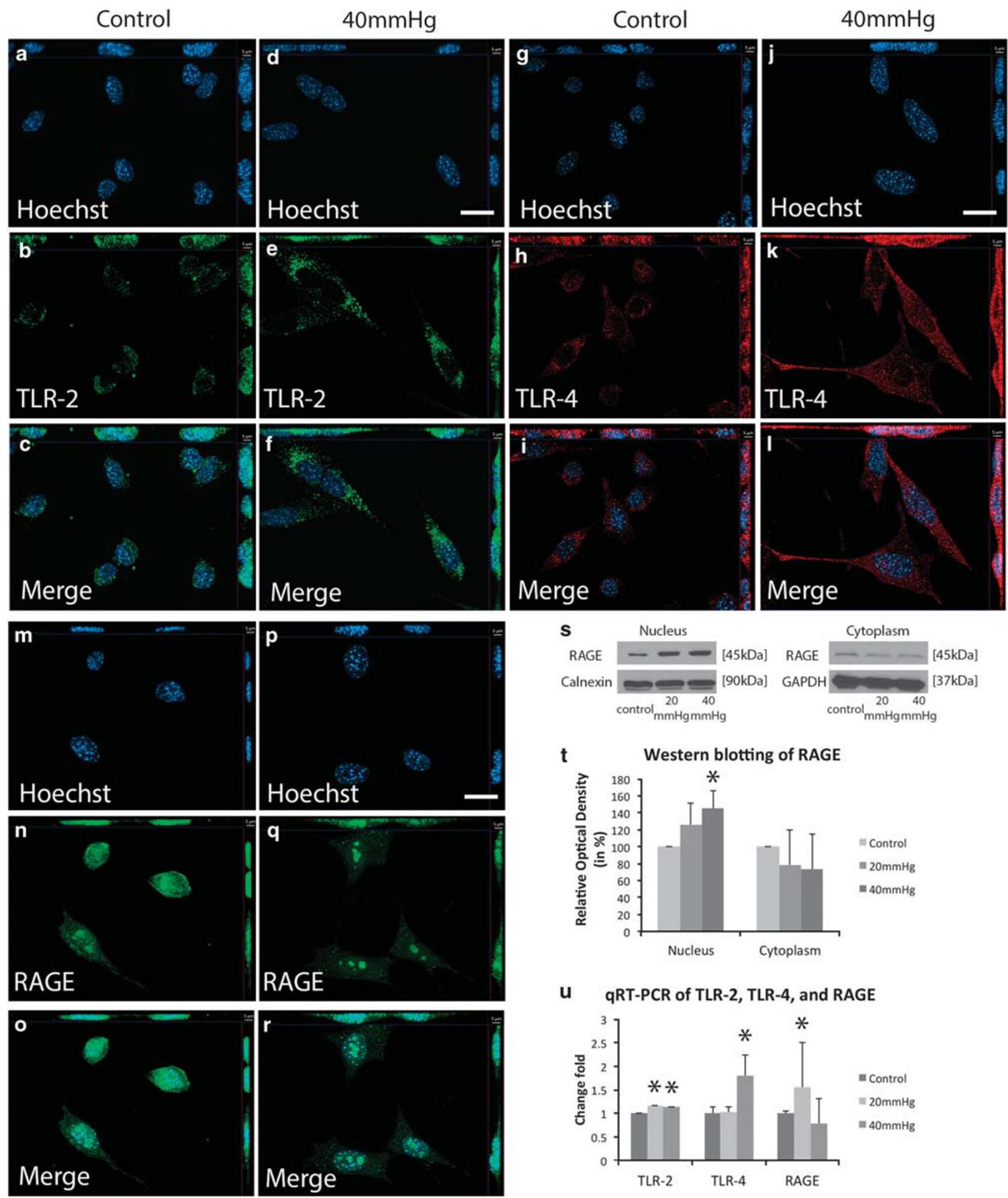




\section{$661 \mathrm{~W}$ cells under elevated pressure}

a

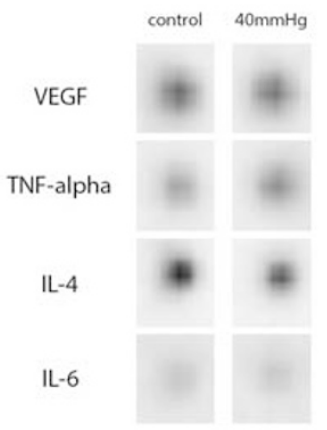

C

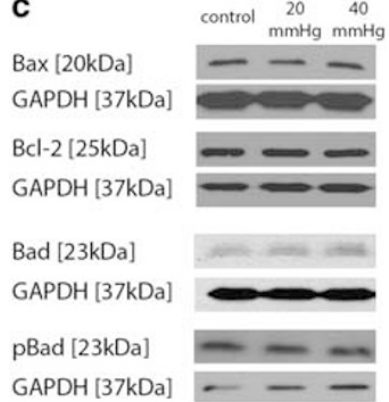

b Cytokine Array of VEGF, TNF-alpha, IL-4,

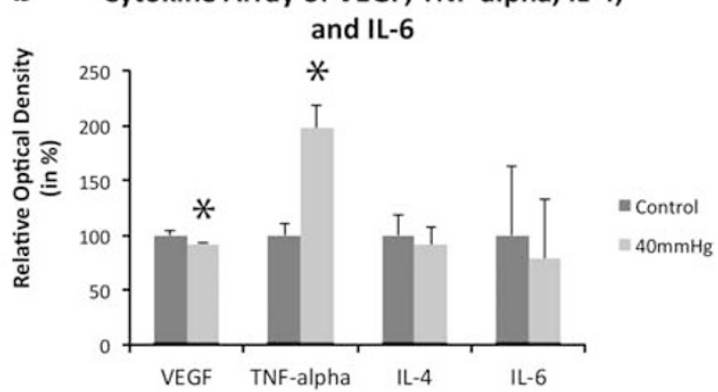

d Western blotting of Bax, Bcl-2, Bad, and $p \mathrm{Bad}$

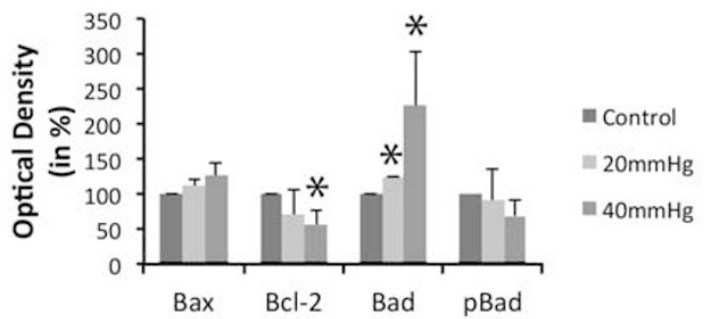

e

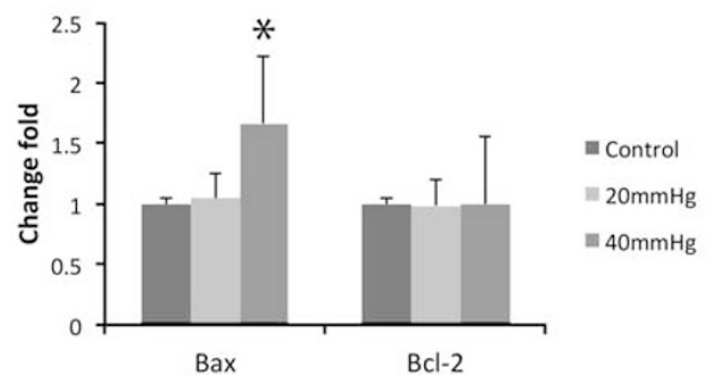

Figure 3 Release of cytokines and expression of apoptosis-related factors by $661 \mathrm{~W}$ cells under elevated pressure. (a) The release of VEGF, TNF- $a$, IL-4, and IL- 6 were examined by cytokine array analysis. (b) Corresponding densitometric analysis of the cytokine array results for VEGF, TNF- $a$, IL-4, and IL- 6 after culture with rHMGB-1 in relation to untreated control. The expression of Bax, Bcl-2, Bad, and $p$ Bad was examined by western blotting analysis. (c) Lysates of $661 \mathrm{~W}$ cells exposed to elevated pressure were prepared and tested for Bax (20 kDa), Bcl-2 (25 kDa), Bad (23 kDa), and pBad (23 kDa). GAPDH $(37 \mathrm{kDa})$ expression verified the amount of protein loaded per lane. (d) Corresponding densitometric analyses of the western blotting results for Bax, $\mathrm{Bcl}-2, \mathrm{Bad}$, and $p \mathrm{Bad}$ with exposure to elevated pressure in relation to unaffected control $(0 \mathrm{~mm} \mathrm{Hg})$. (e) qRT-PCR results for Bax and Bcl-2 mRNA levels in $661 \mathrm{~W}$ cells exposed to elevated pressure $(20,40 \mathrm{~mm} \mathrm{Hg})$ in relation to unaffected control $(0 \mathrm{~mm} \mathrm{Hg})$. ${ }^{*}$ Statistically significant differences at $P<0.05$.

Figure 2 Expression of TLR-2, TLR-4, and RAGE by $661 \mathrm{~W}$ cells under elevated pressure. Immunofluorescence microscopy of expression and intercellular localization of (a-f) TLR-2 (Alexa 488, green), (g-I) TLR-4 (Alexa 594, red), and (m-r) RAGE (Alexa 488, green) in 661W cells under elevated pressure. Cell nuclei were stained with bisbenzimide (Hoechst 33342, blue). Apotome images by $z$-planes stacks at $0.5-\mu \mathrm{m}$ (TLR-2), $0.35-0.47-\mu \mathrm{m}$ (TLR-4), and 0.4- $\mu \mathrm{m}$ (RAGE) intervals: bottom of each panel is an $x y$ en face view of the presented cell layer shown in maximum-intensity projection through the $z$-axis. Top and side of each panel is a cross-section through the z-plane of multiple optical slides. The expression of HMGB-1 was examined by western blotting analysis. (s) Nucleus/membrane and cytoplasmic lysates of $661 \mathrm{~W}$ cells exposed to elevated pressure were prepared and tested for RAGE (45 kDa). Calnexin $(90 \mathrm{kDa})$ and GAPDH (37 kDa) expression verified the amount of protein loaded per lane. (t) Corresponding densitometric analyses of the western blotting results for RAGE with exposure to elevated pressure in relation to unaffected control $(0 \mathrm{~mm} \mathrm{Hg})$. (u) qRT-PCR results for TLR-2, TLR-4, and RAGE mRNA levels in $661 \mathrm{~W}$ cells exposed to elevated pressure $(20 \mathrm{~mm} \mathrm{Hg}, 40 \mathrm{~mm} \mathrm{Hg})$ in relation to unaffected control $(0 \mathrm{~mm} \mathrm{Hg}) . \mathrm{Scale}$ bar, $20 \mu \mathrm{m}$. *Statistically significant differences at $P<0.05$. 
$661 \mathrm{~W}$ cells under elevated pressure

a

MTT of $661 \mathrm{~W}$ cells
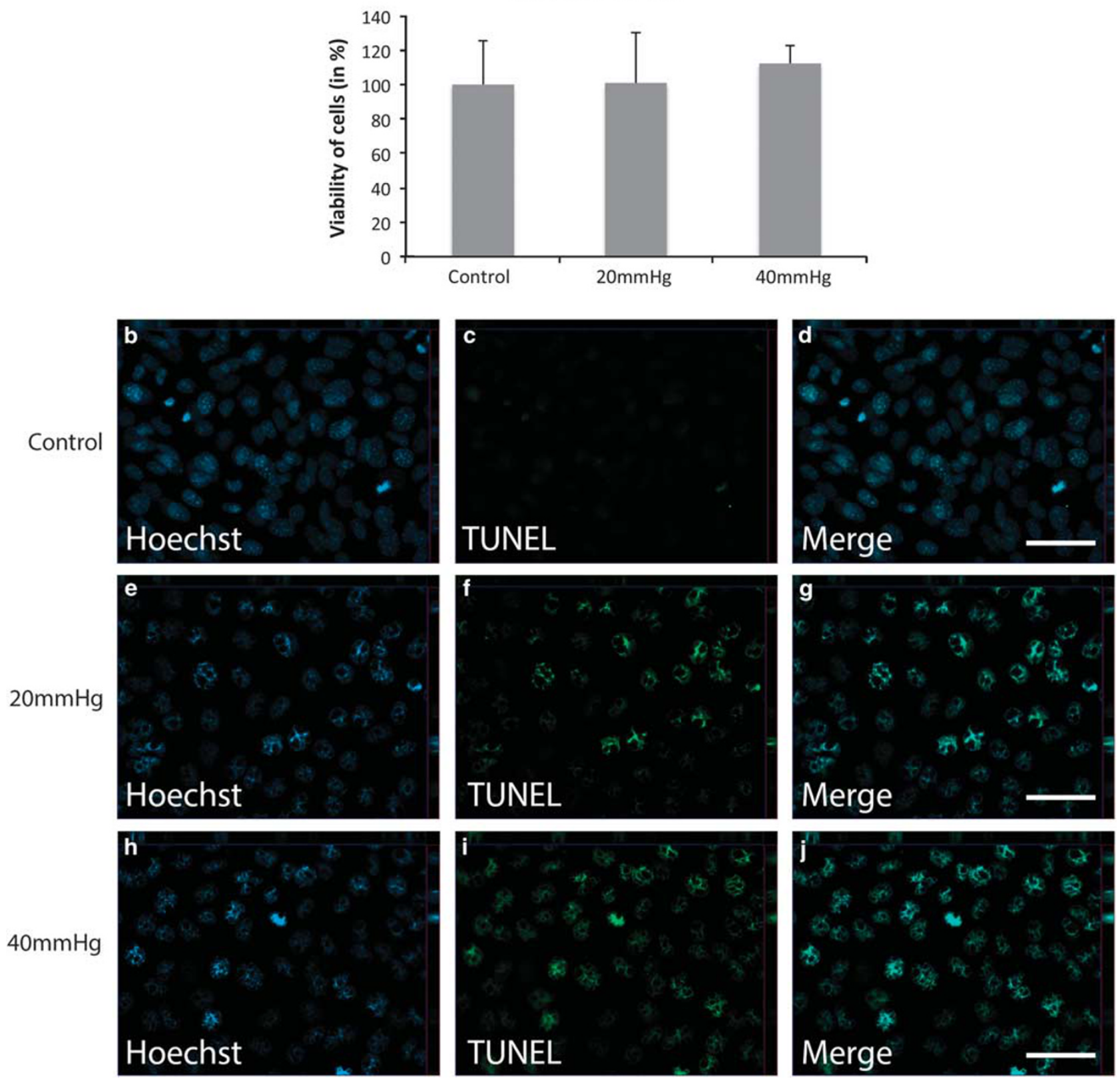

Figure 4 Viability and apoptosis of $661 \mathrm{~W}$ cells under elevated pressure. $661 \mathrm{~W}$ cells were tested under elevated pressure $(20,40 \mathrm{~mm} \mathrm{Hg}) . \mathrm{Un}-\mathrm{exposed}$ $661 \mathrm{~W}$ cells served as controls. (a) The viability of these cells was evaluated using the 3-(4,5-dimethylthiazol-2-yl)-2,5-diphenyl tetrazolium bromide (MTT) assay. No statistically significant alterations were found between any of the tested conditions $(P>0.05)$. (b-j) Apoptosis in $661 \mathrm{~W}$ cells exposed to elevated pressure was studied using the TUNEL assay (green). Cell nuclei were stained with bisbenzimide (Hoechst 33342, blue). Multiple layer images by $z$-planes stacks at $0.5-0.52-\mu \mathrm{m}$ intervals: bottom of each panel is an xy en face view of the presented cell layer shown through the $z$-axis. Top and side of each panel is a cross-section through the $z$-plane of multiple optical slides. Scale bar, $50 \mu \mathrm{m}$.

\section{Apoptosis-Related Factors Under Elevated Pressure}

With respect to apoptosis-related factors in $661 \mathrm{~W}$ cells cultivated under elevated pressure conditions, there was a tendency of an increase of protein expression verified with WB of pro-apoptotic Bax (20 mm Hg: $112.1 \pm 9.2 \%, P=0.1$;
$40 \mathrm{~mm} \mathrm{Hg:} 126.5 \pm 17.5 \%$; $P=0.08)$ together with a statistically significant increase of Bad $(20 \mathrm{~mm} \mathrm{Hg}: 125.1 \pm 0.1 \%$, $P<0.05 ; \quad 40 \mathrm{~mm} \mathrm{Hg:} 226.2 \pm 77.7 \%, \quad P<0.05) \quad$ compared with control. Moreover, a decrease of antiapoptotic Bcl-2 expression $(20 \mathrm{~mm} \mathrm{Hg}$ : $70.5 \pm 35.7 \%, \quad P=0.4 ; 40 \mathrm{~mm} \mathrm{Hg}$ : 


\section{Co-cultivation of $661 \mathrm{~W}$ cells with rHMGB-1}

a

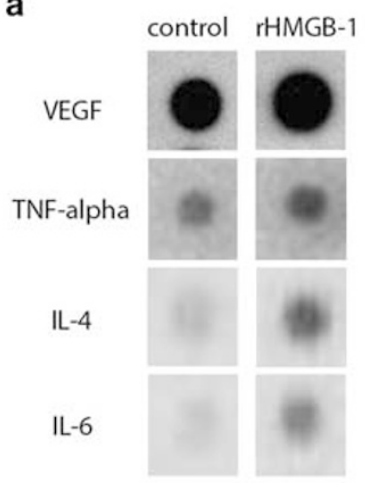

C

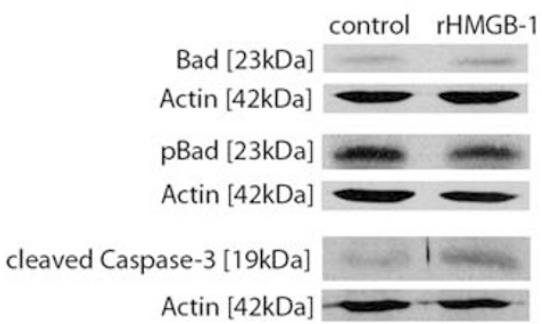

b
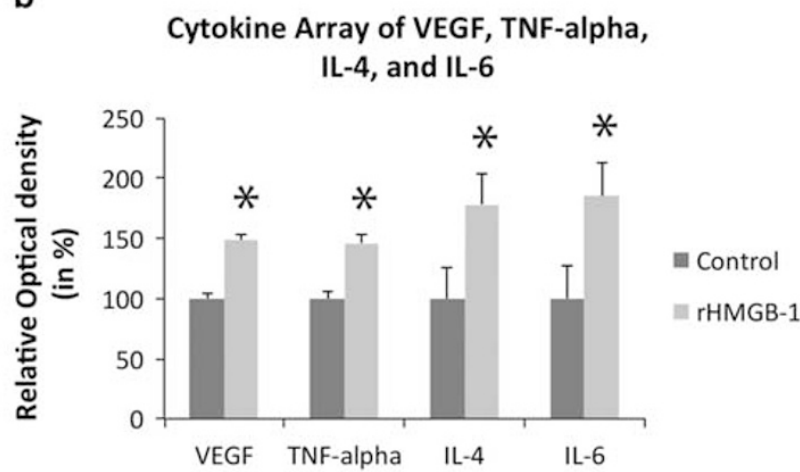

d Western blotting of Bad, $p$ Bad, and cleaved caspase-3

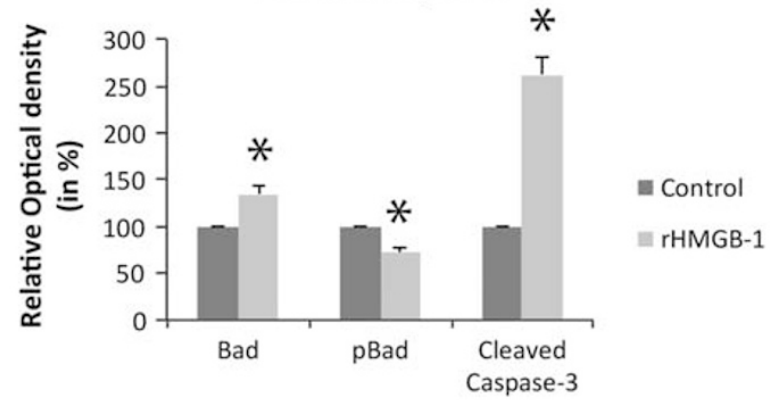

MTT of $661 \mathrm{~W}$ cells

e

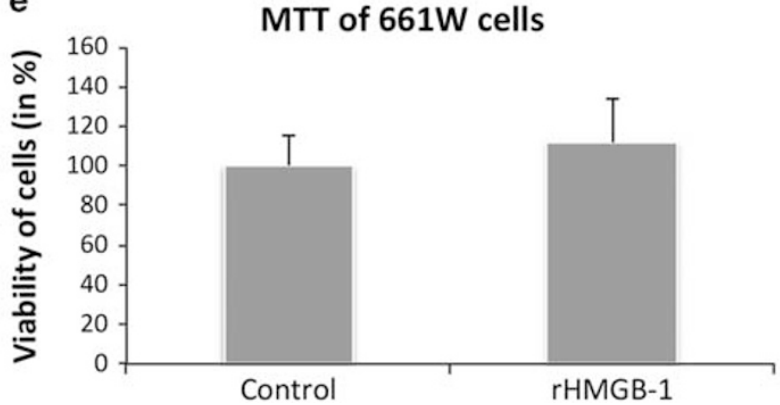

Figure 5 Release of cytokines, expression of apoptosis-related factors, viability, and apoptosis of 661W cells after co-culturing with recombinant HMGB-1 (rHMGB-1). (a) The release of vascular-endothelial growth factor (VEGF), tumor necrosis factor-alpha (TNF- $a$ ), interleukin-4 (IL-4), and IL-6 were examined by cytokine array analysis. (b) Corresponding densitometric analyses of the cytokine array results for VEGF, TNF- $a$, IL-4, and IL- 6 after culture with rHMGB-1 in relation to untreated control. The expression of Bad, pBad, and cleaved Caspase-3 were examined by western blotting analysis. (c) Lysates of $661 \mathrm{~W}$ cells cultured with rHMGB-1 were prepared and tested for Bad (23 kDa), pBad ( $23 \mathrm{kDa})$, and cleaved Caspase-3 (19 kDa). Actin (42 kDa) expression verified the amount of protein loaded per lane. (d) Corresponding densitometric analyses of the western blotting results for Bad, $p$ Bad, and cleaved Caspase- 3 with and without exposure to rHMGB-1. (e) The viability of $661 \mathrm{~W}$ cells exposed to rHMGB-1 was evaluated using the MTT assay. No statistically significant alterations were found between any of the tested conditions $(P>0.05)$. (f-k) Apoptosis in $661 \mathrm{~W}$ cells exposed to rHMGB-1 was studied using the TUNEL assay (green). Cell nuclei were stained with bisbenzimide (Hoechst 33342, blue). Multiple layer images by $z$-planes stacks at $0.94-\mu \mathrm{m}$ intervals: bottom of each panel is an $x y$ en face view of the presented cell layer shown in maximum-intensity projection through the $z$-axis. Top and side of each panel is a cross-section through the $z$-plane of multiple optical slides. Scale bar, $50 \mu \mathrm{m}$. ${ }^{*}$ Statistically significant differences at $P<0.05$.

$58.9 \pm 20.9 \%, \quad P<0.05)$ together with a not significant decrease of $p$ Bad $(20 \mathrm{~mm} \mathrm{Hg:} 91.7 \pm 43.2 \%, \quad P=0.7$; $40 \mathrm{~mm} \mathrm{Hg:} \quad 69.0 \pm 22.3 \%, \quad P=0.1)$ has been found (Figures $3 \mathrm{c}$ and $\mathrm{d}$ ).

The gene-expression levels of apoptosis-related factors Bax and Bcl-2 were examined using qRT-PCR. The expression levels of pro-apoptotic Bax increased slightly in the $40 \mathrm{~mm} \mathrm{Hg}$ group (20 mm Hg: RQ $1.04 \pm 0.2, P=0.4 ; 40 \mathrm{~mm} \mathrm{Hg:} \mathrm{RQ}$ $1.7 \pm 0.6, P<0.05)$ compared with control, while that of the anti-apoptotic Bcl-2 mRNA remained stable under both pressure conditions $(20 \mathrm{~mm} \mathrm{Hg}$ : RQ $1.0 \pm 0.1, \quad P=0.8$; $40 \mathrm{~mm} \mathrm{Hg}$ : RQ $1.0 \pm 0.1, P=0.1$; Figure $3 \mathrm{e})$. The findings 

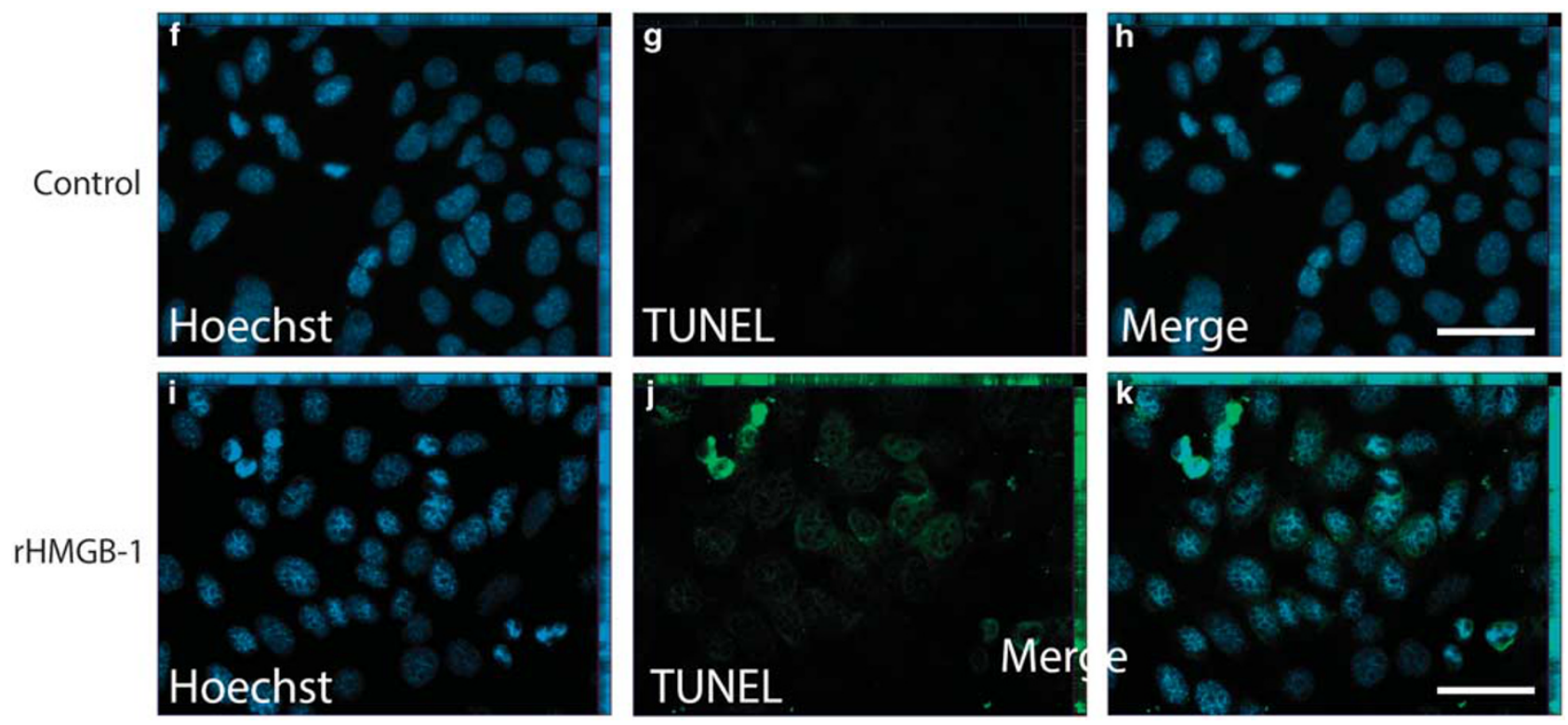

Figure 5 Continued.

promote the pro-apoptotic role of HMGB-1 within $661 \mathrm{~W}$ cells under elevated pressure.

\section{Cell Viability And Apoptosis Under Elevated Pressure}

The viability of $661 \mathrm{~W}$ cells was first studied using MTT assay to exclude impairment owing to elevated pressure. No statistically significant alterations in viability were found between $661 \mathrm{~W}$ cells exposed to elevated air pressure (20 mm Hg: $\quad 100.6 \pm 29.9 \%, \quad P=0.98 ; \quad 40 \mathrm{~mm} \mathrm{Hg}$ : $112.0 \pm 10.3 \%, P=0.5)$ relative to control $(100.0 \pm 28.9 \%$; Figure 4a). Next, related apoptosis in $661 \mathrm{~W}$ cells due to elevated pressure were explored by TUNEL assay. A significant elevation of apoptotic $661 \mathrm{~W}$ cells was found in the $20 \mathrm{~mm} \mathrm{Hg} \quad(52.7 \pm 6.2 \%, \quad P<0.05)$ and $40 \mathrm{~mm} \mathrm{Hg}$ $(65.6 \pm 5.6 \%, \quad P<0.05)$ groups compared with control $(8.6 \pm 4.1 \%$; Figures $4 \mathrm{~b}-\mathrm{j})$. Thus non-apoptotic $661 \mathrm{~W}$ cells exposed to elevated pressure retained the viability compared with unaffected cells.

\section{HMGB-1 Effects on Cultured Cells}

To study the HMGB-1-associated influence of cytokines and apoptosis-related factors, $661 \mathrm{~W}$ cells were exposed to rHMGB-1.

First, $661 \mathrm{~W}$ cells were cultured with rHMGB-1 to study the release of cytokines, which are related to immunological reactions in, for example, retinal disorders and glaucoma (eg, VEGF, TNF- $\alpha$, IL-4, and IL-6). Dot-blot analysis revealed an increase in the release of VEGF $(148.8 \pm 5.1 \%, P<0.05)$, TNF- $\alpha \quad(146.2 \pm 6.5 \%, \quad P<0.05), \quad$ IL-4 $\quad(178.3 \pm 25.2 \%$, $P<0.05)$, and IL-6 $(184.7 \pm 27.9 \%, P<0.05)$ after exposure to rHMGB-1 compared with the control (Figures $5 \mathrm{a}$ and $\mathrm{b}$ ). These data show that $661 \mathrm{~W}$ cells respond to exogenous application of rHMGB-1 to the culture medium.
Moreover, the response of $661 \mathrm{~W}$ cells exposed to external rHMGB-1 was assessed by analyzing the expression of apoptosis-related factors, the viability, and the related apoptosis by TUNEL. Analyses of apoptosis-associated factors revealed an increase in the pro-apoptotic factor Bad $(134.7 \pm 9.3 \%$, $P<0.05)$ and cleaved Caspase-3 $(262.5 \pm 18.6 \%, P<0.05)$ and a slight decrease in $p \mathrm{Bad}(72.6 \pm 5 \%, P<0.05)$ compared with the control (Figures $5 \mathrm{c}$ and $\mathrm{d}$ ). These data indicate the elevation of pro-apoptotic factors within $661 \mathrm{~W}$ cells after rHMGB-1 exposure. The viability studied by MTT assay revealed comparable results between $661 \mathrm{~W}$ cells exposed to rHMGB-1 (111.8 $\pm 22.3 \%)$ and control $(100.0 \pm 14.8 \%$, $P=0.5$; Figure 5e). Thus rHMGB-1 did not change the viability of exposed $661 \mathrm{~W}$ cells compared with unaffected cells. Apoptosis in 661W cells exposed to rHMGB-1 were explored with TUNEL assay. Apoptosis occurred in 661W cells exposed to rHMGB-1 $(44.7 \pm 9.4 \%)$ compared with control $(5.5 \pm 1.3 \%, P<0.05$; Figures $5 \mathrm{f}-\mathrm{k})$. The results indicate that rHMGB-1 may not influence the viability but induce apoptosis in $661 \mathrm{~W}$ cells compared with control.

\section{Retinal Explants}

The influence of elevated pressure on retinal explants was investigated. First, the HMGB-1 release $(20 \mathrm{~mm} \mathrm{Hg}$ : $355.2 \pm 367.0 \%, P=0.4 ; 40 \mathrm{~mm} \mathrm{Hg:} 253.0 \pm 160.5 \%, P=0.3)$ in the supernatants of retinal explants exposed to elevated pressure remained unchanged (Figures $6 \mathrm{a}$ and $\mathrm{b}$ ).

The gene-expression levels of HMGB-1, RAGE, TLR-2, TLR-4, Bax, and Bcl-2 were examined by qRT-PCR. There was an increase in HMGB-1 mRNA under elevated pressure (20 mm Hg: RQ $4.0 \pm 0.7, P<0.05$; $40 \mathrm{~mm}$ Hg: RQ $3.5 \pm 0.4$, $P<0.05)$. With respect to HMGB-1-associated factors, there was an increase in TLR-2 (20 mm Hg: RQ 5.6 $\pm 2.8, P<0.05$; 


\section{Retinal explants under elevated pressure}

a
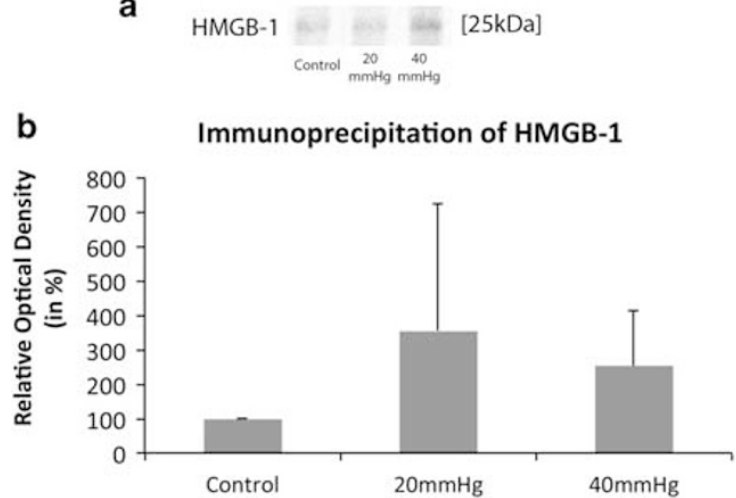

C

qRT-PCR of HMGB-1, TLR-2, TLR-4, and RAGE

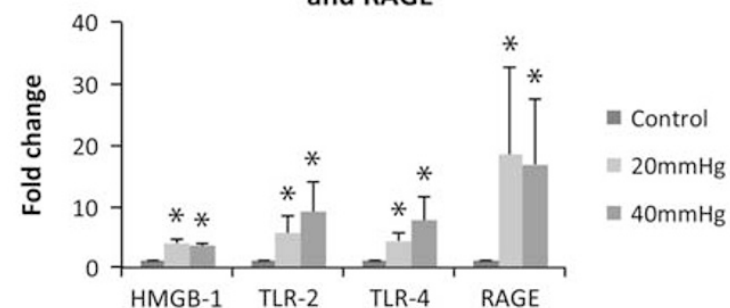

d

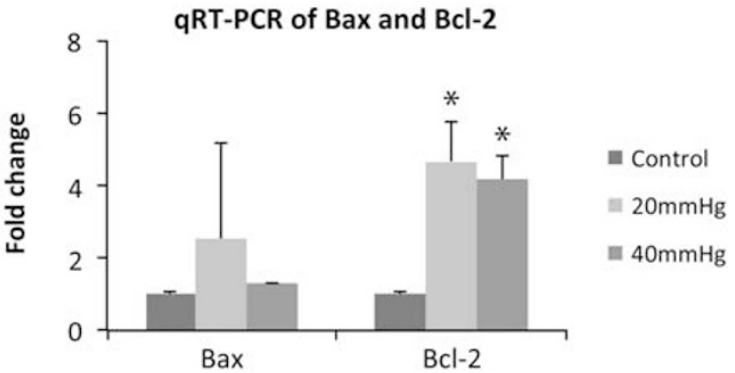

Figure 6 Expression of HMGB-1, TLR-2, TLR-4, RAGE, and apoptoticrelated mRNA levels in retinal explants under elevated pressure. (a) Immunoprecipitation of HMGB-1 in supernatants of retinal explants exposed to elevated pressure $(20,40 \mathrm{~mm} \mathrm{Hg})$ in relation to unaffected control. (b) Corresponding densitometric analysis of the immunoprecipitation results for HMGB-1 in retinal explants exposed to elevated pressure in relation to untreated control. qRT-PCR results for HMGB-1, TLR-2, TLR-4, RAGE, Bax, and Bcl-2 mRNA levels of retinal explants exposed to elevated pressure $(20,40 \mathrm{~mm} \mathrm{Hg})$. (c) HMGB-1, the HMGB-1-related factors TLR-2, TLR-4, and RAGE, and (d) apoptosisassociated Bax and Bcl-2 in relation to unaffected control. *Statistically significant differences at $P<0.05$.

40 mm Hg: RQ 9.2 \pm 5.0, $P<0.05)$, TLR -4 (20 mm Hg: RQ $4.4 \pm 1.4, P<0.05 ; 40 \mathrm{~mm} \mathrm{Hg}: \mathrm{RQ} 7.8 \pm 3.7, P<0.05)$, and RAGE (20 mm Hg: RQ 18.5 $\pm 14.4, P<0.05 ; 40$ mm Hg: RQ $16.9 \pm 10.6, P<0.05)$ mRNAs compared with the control (Figure $6 \mathrm{c}$ ). With regard to the apoptosis-associated factors, there was an increase in the mRNA expression for antiapoptotic Bcl-2 (20 mm Hg: RQ $4.7 \pm 1.1, \quad P<0.05$; $40 \mathrm{~mm} \mathrm{Hg}$ : RQ $4.2 \pm 0.6, \quad P<0.05)$ and an unchanged expression of that for the pro-apoptotic Bax in both the
$20 \mathrm{~mm} \mathrm{Hg}$ (RQ 2.5 $\pm 2.6, P=0.3$ ) and $40 \mathrm{~mm} \mathrm{Hg}$ groups (RQ $1.3 \pm 0.3, P=0.1$ ) (Figure $6 \mathrm{~d}$ ).

Finally, the response of retinal explants to external rHMGB-1 exposure was examined by culturing the explants with $1 \mu \mathrm{g} / \mathrm{ml}$ rHMGB-1. HMGB- 1 and associated factors such as TLR-2, TLR-4, and RAGE and apoptosis-related factors were analyzed. The mRNA levels of HMGB-1 increased under the influence of rHMGB-1 (RQ 5.9 $\pm 0.2, P<0.05$ ) relative to control. The expression of TLR-2 was increased (RQ 5.9 \pm 0.6 , $P<0.05$ ) while that of TLR-4 remained stable (RQ $1.1 \pm 0.03$, $P=0.2)$ compared with control. The mRNA expression of RAGE increased under the influence of rHMGB-1 (RQ $19.6 \pm 0.01, P<0.05)$ compared with control (Figure 7a).

In relation to the release of cytokines, a decrease of TNF- $\alpha$ (68.6 $\pm 4.4 \%, P<0.05)$ compared with control was detected. The release of VEGF $(52.1 \pm 26.6 \%, \quad P=0.1), \quad$ IL-4 $(92.9 \pm 10.6 \%, P=0.44)$, and IL-6 $(134.8 \pm 23.3 \%, P=0.17)$ remained unchanged (Figures $7 \mathrm{~b}$ and $\mathrm{c}$ ).

Regarding the apoptotic factors, there was an increase in the mRNA expression of the prosurvival factor Bcl-2 (RQ $6.1 \pm 0.2, P<0.05)$ and a slight decrease in that of the pro-apoptotic factor Bax (RQ 0.3 $\pm 0.004, P<0.05$; Figure 7d). In summary, retinal explants exposed to elevated pressure or rHMGB-1 exhibited upregulation of HMGB-1-associated receptors and apoptosis-associated members of the pro-survival programs within the retinal tissue.

Apoptosis within various cell types of retinal explants exposed to rHGMB-1 were studied by TUNEL assay. $\beta$-III Tubulin-positive RGCs (Figures 8a-f) and rhodopsin-positive photoreceptors (Figures $8 \mathrm{~g}-\mathrm{l}$ ) show distinct apoptosis related to exogenous rHMGB-1 exposure. This supports the findings in $661 \mathrm{~W}$ cells owing to response of photoreceptors exposed to rHMGB-1. As anticipated, the HMGB-1-treated explants have largely lost their histotypical lamination (Figures $8 \mathrm{~g}-1$ ), confirming that multiple subsets of neurons are affected. In contrast, apoptosis was not found in GFAP-positive astrocytes (Figures 8m-r), Iba-1-positive microglial cells (Figures 8s-x), and calretinin-positive amacrine cells (data not shown).

These results promote the differential cellular responses in the retina owing to HMGB-1 exposure, being compatible with the different vulnerabilities of different cell types to external cellular stress. Moreover, the missing apoptosis in retinal cells associated with stress mechanisms promotes the suggested switch of the retinal environment into a pro-survival state evoked by HMGB-1.

\section{DISCUSSION}

To our knowledge, there are no other data published on the response of $661 \mathrm{~W}$ cells and retinal explants to elevated pressure in association with HMGB-1. The principal findings of this study are as follows:

(1) Photoreceptors (661W cells) respond to elevated pressure in vitro. 


\section{Co-cultivation of retinal explants with rHMGB-1}

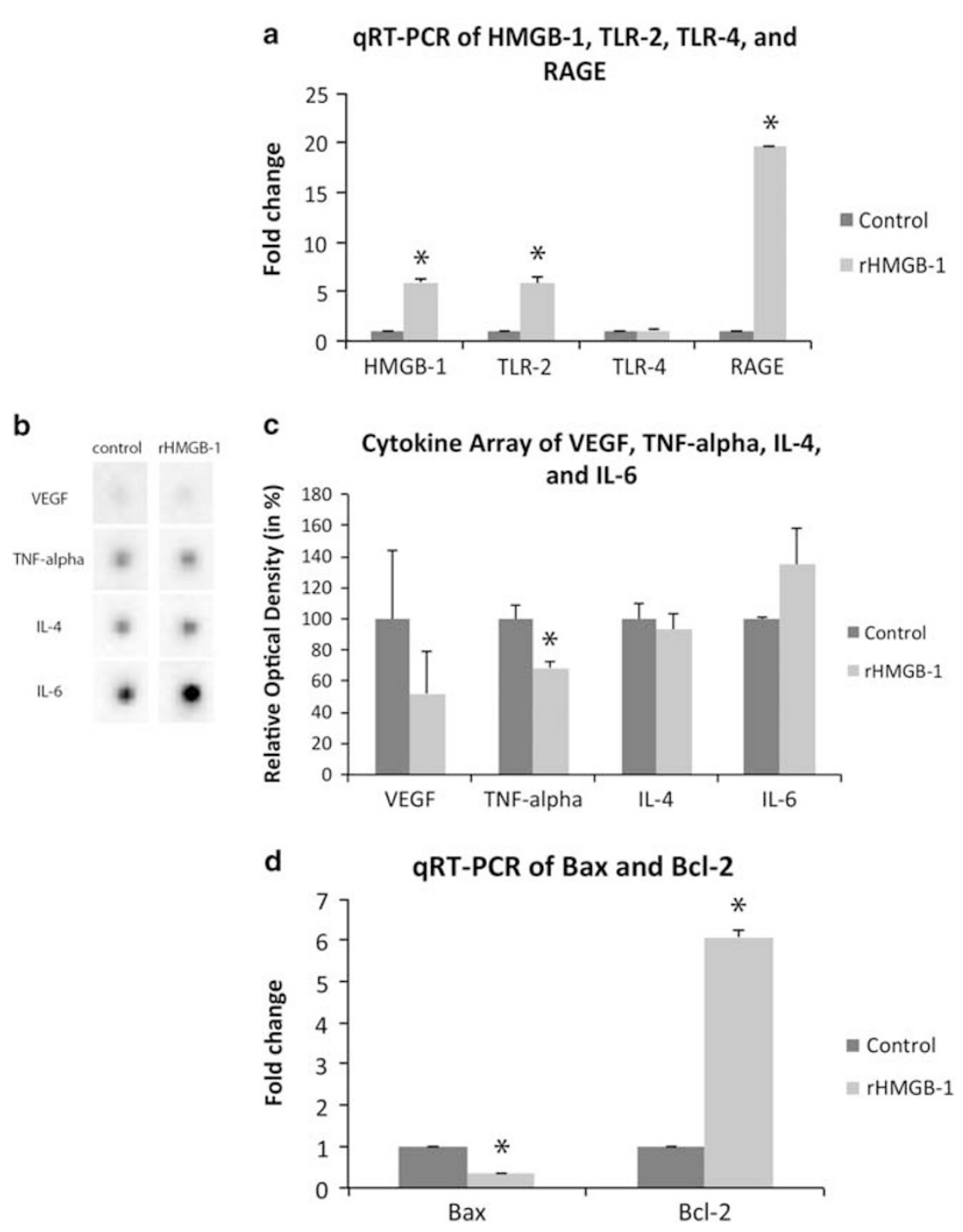

Figure 7 Expression of HMGB-1, TLR-2, TLR-4, RAGE, release of cytokines, and apoptotic-related mRNA levels in retinal explants after co-culturing of retinal explants with rHMGB-1. qRT-PCR results for (a) HMGB-1, TLR-2, TLR-4, and RAGE mRNA-levels in retinal explants exposed to rHMGB-1 in relation to unaffected control. (b) The release of VEGF, TNF- $a$, IL-4, and IL- 6 were examined by cytokine array analysis. (c) Corresponding densitometric analysis of the cytokine array results for VEGF, TNF- $a$, IL-4, and IL-6 after culture with rHMGB-1 in relation to control. (d) qRT-PCR results for apoptosis-associated $\mathrm{BCl}-2$ and $\mathrm{Bax}$ in retinal explants exposed to $\mathrm{rHMGB}-1$ in relation to control. *Statistically significant differences at $P<0.05$.

(2) HMGB-1 is released by and regulated in $661 \mathrm{~W}$ cells and retinal explants under elevated pressure.

(3) An increase of the immunological factors RAGE, TLR-2, and TLR- 4 were found in pressure-affected $661 \mathrm{~W}$ cells and retinal explants.

(4) Apoptosis and an increase of pro-apoptotic factors (eg, Bad) was found in elevated pressure-and in exogenous rHMGB-1-exposed 661W cells.

(5) Exogenous rHMGB-1 promotes cytokine release from $661 \mathrm{~W}$ cells.

(6) Exogenous rHMGB-1 regulates apoptosis-related members and the immunological factors RAGE and
TLR-2 and drives the retinal environment into a proinflammatory and pro-survival way in retinal explants.

The main focus of the presented work was to study the role of HMGB-1 and its potential inflammatory and apoptotic response in retinal photoreceptors affected with elevated pressure. Finally, the role of elevated pressure and/or endogenous HGMB-1 exposure was proofed in retinal explants to detect possible alterations in the complex retinal homeostasis. The provided studies of mRNA expression levels without presentation of related proteins in retinal explants are a limitation of the study. Nevertheless, the observed role of 


\section{Co-cultivation of retinal explants with rHMGB-1}
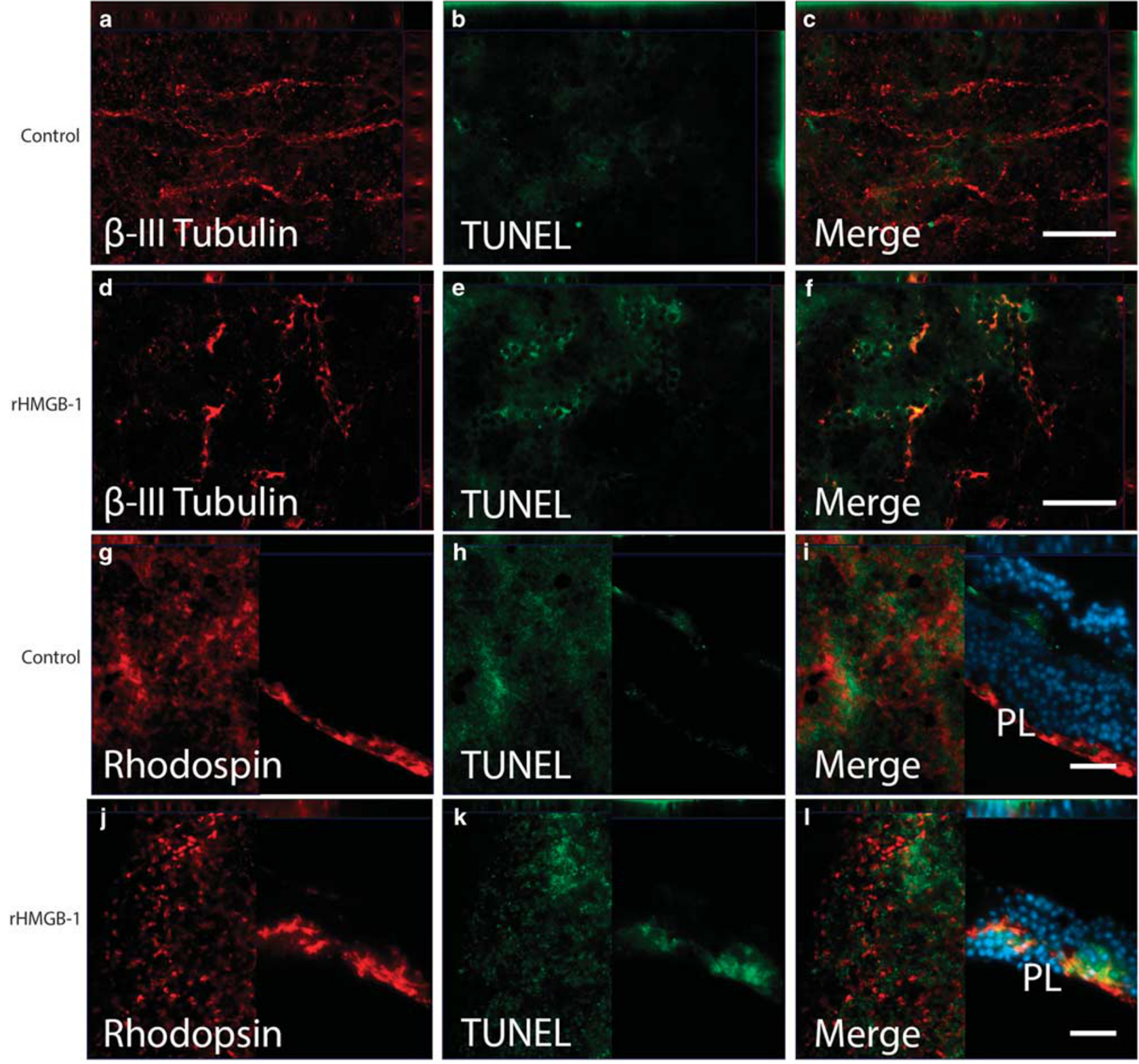

Figure 8 Apoptosis in distinct retinal cell types after co-culturing of retinal explants with rHMGB-1. Apoptosis in retinal explants as well as retinal section (for photoreceptors) exposed to rHMGB-1 was studied using the TUNEL assay (green). The related retinal cell types were stained with $\beta$-III tubulin (Alexa 594, red) detecting retinal ganglion cells (a-f) and rhodopsin (Alexa 594, red) detecting photoreceptors (g-l, left panel indicating whole mounts, right panel indicating retinal sections). In the control, virtually no TUNEL-positive nuclei (green) are observed within rhodopsin-stained photoreceptor layer (PL; red) (g-i). In the HMGB-1-treated retinal explants, TUNEL-positive staining (green) was observed within the inner aspect of the photoreceptor layer, which is partially outlined by the appearance of rhodopsin (red) (j-I). Antibodies detecting Glial fibrillary acidic protein (GFAP, Alexa 594 , red) were used to detect astrocytes $(\mathbf{m}-\mathbf{r})$ and ionized calcium-binding adaptor molecule 1 (Iba-1, Alexa 594, red) to detect microglial cells (s-x). Cell nuclei were stained with bisbenzimide (Hoechst 33342, blue) within retinal sections. The negative control was performed with Alexa 594 secondary antibody alone (data not shown). Images were represented as multiple layer images by $z$-plane stacks. Panels of retinal whole mounts showing retinal ganglion cells, astrocytes, and microglial cells are an $x y$ en face view from the inner retina in projection through the $z$-axis. Panels showing photoreceptors are an $x y$ en face view from the choroidal side as well as retinal sections. Top and side of each panel is a cross-section through the $z$-plane of multiple optical slides. Scale bars, (c, $\mathbf{f}, \mathbf{o}, \mathbf{r}, \mathbf{u}$ and $\mathbf{x}$; retinal whole mounts) $50 \mu \mathrm{m}$; ( $\mathbf{r}$ and $\mathbf{l}$; retinal sections) $20 \mu \mathrm{m}$.

HMGB-1 within photoreceptors exposed to elevated pressure together with the response of mRNA expression in the complex retinal network highly promote the link between elevated pressure and HMGB-1 as well as inflammation and apoptosis.
Cytosolic HMGB-1 can translocate to the nucleus, bind to DNA, and regulate gene expression. Several activated immune cells (eg, macrophages, monocytes, and dendritic cells) release HMGB-1 via the leaderless secretory pathway. ${ }^{27}$ It has been 

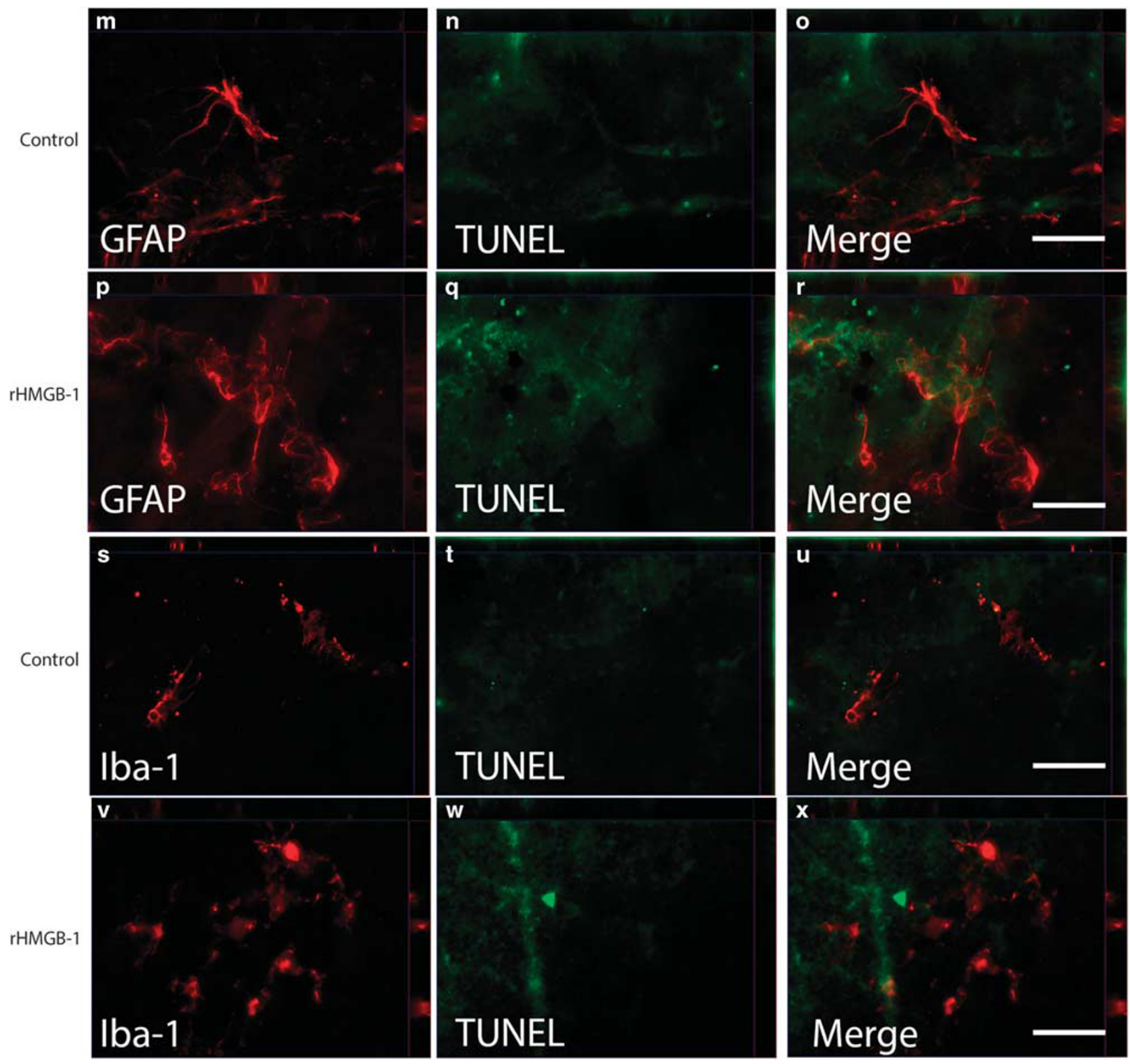

Figure 8 Continued.

suggested that HMGB-1 itself can signal through RAGE, TLR-2, and TLR-4. ${ }^{28-30}$ Engagement of RAGE by extracellular HMGB-1 triggers the activation of pro-inflammatory signaling pathways, such as those resulting in elaboration of reactive oxygen intermediates and activation of NF- $\kappa \mathrm{B} .{ }^{31-34}$ Previous studies have shown that HMGB-1 promotes the inflammatory response. ${ }^{33,35}$ Elevated levels of HMGB-1 have previously been found in the retinas of glaucomatous rats, ${ }^{21}$ indicating that glaucoma is associated with degenerative processes.

Activation of the TLR-4 signaling pathway by its ligands initiates the inflammatory response via downstream signaling, which results in $\mathrm{NF}-\kappa \mathrm{B}$ activation and the production of pro-inflammatory cytokines in ischemia/reperfusion by injury, trauma, and hemorrhagic shock. ${ }^{36-41}$ The mechanism underlying inflammation involves binding to TLR-4, which mediates the HMGB-1-dependent activation of macrophage cytokine release. ${ }^{42}$

The study promotes the upregulation of RAGE, TLR-2, and TLR-4 in $661 \mathrm{~W}$ cells as well as retinal explants exposed to elevated pressure. Together with immune cells, the levels of RAGE, TLR-2, and TLR- 4 in $661 \mathrm{~W}$ cells as well as retinal explants appear to be correlated with the released HMGB-1. Activation of TLR-2, TLR-4, and RAGE signaling owing to pressure-related release of HMGB-1 may thus result in the detected cytokine release in $661 \mathrm{~W}$ cells. Interestingly, the mRNA expression of TLR-4 in retinal explants exposed to 
exogenous rHMGB-1 was not increased in contrast to retinal explants cultured under elevated pressure conditions. This may point to an additional regulatory pathway induced by elevated pressure in retinal tissues that cannot be induced by exogenous HMGB-1 itself.

The findings of TUNEL staining and increase in Bad and Bax activity, together with decreased Bcl-2 activity in 661W cells exposed to elevated pressure, indicates that this induces apoptosis. The elevation in TUNEL-positive 661W cells as well as the increase in Bad and Caspase 3 activity in 661W cells exposed to rHMGB1 gives further evidence that elevated pressure induces apoptosis in photoreceptor cells via HMGB1.

HMGB-1 is released by both inflammatory cell activation and necrosis. The mechanisms of this release are distinct, and necrotic cells appear to be one of them, because the permeability of the nuclear and cellular membranes within necrosis may allow a passive exit process. ${ }^{4-45}$ In contrast, HeLa cells undergoing apoptosis exhibited active release of HMGB- $1 .{ }^{45}$ In the present study, we found a release of HMGB-1 by $661 \mathrm{~W}$ cells exposed to elevated pressure. The findings of apoptosis together with stable signs of viability increased intracellular HMGB-1, and elevation of related mRNA levels presume that HMGB-1 release by $661 \mathrm{~W}$ cells exposed to elevated pressure occurred by an active way as well as as a part of the apoptotic pathway.

VEGF, TNF- $\alpha$, IL- 4 , and IL- 6 are members of the cytokine family, which are immunomodulating and neuromodulating factors that exert their effects on cells only after binding to specific receptors on the cell surface. Several cytokines were reported to have roles in the immune system. ${ }^{46}$ VEGF exerts an inflammatory response and has been found in several retinal diseases, such as age-related macular degeneration and diabetic retinopathy. However, RAGE-dependent secretion and expression of VEGF indicate an inflammatory response through alterations in vascular permeability and angiogenesis. ${ }^{44,47,48}$ The findings of the present study demonstrate the existence of HMGB-1-associated release of VEGF within the retina, indicating that the increase in vascular permeability and breakdown of the blood-retina barrier in cases of glaucoma may be mediated secondarily by endogenous HMGB-1.

TNF- $\alpha$ is an important proinflammatory cytokine with several biological effects and is an initiator of the immune response. ${ }^{49}$ It is related to various manifestations of bacterial or viral infections and neoplastic or autoimmune diseases. ${ }^{50}$ TNF- $\alpha$ stimulates the secretion of components of the IL- 1 system as well as IL-6 within the vitreoretinal compartment. ${ }^{51,52}$ Increased cytoplasmic expression and extracellular deposition of HMGB-1 are found in the affected tissues of rheumatic diseases, such as arthritis, polymyositis, and dermatomyositis. TNF- $\alpha$ and IL- $1 \beta$ are co-expressed in extracellular areas where HMGB-1 is present. Together with TNF- $\alpha$ and IL- $1 \beta$, HMGB-1 may form a proinflammatory loop that promotes the process of chronic inflammation. ${ }^{53}$ The present data suggest that elevated pressure as well as endogenous HMGB-1 influences the expression of TNF- $\alpha$ in $661 \mathrm{~W}$ cells in vitro. The HMGB-1-associated increase in TNF- $\alpha$ indicates some kind of influence on the secondary inflammation response in $661 \mathrm{~W}$ cells owing to elevated pressure.

IL-4 induces the differentiation of naive helper T-cells to Th2 cells and stimulates the proliferation of B- and T-cells and decreases the production of Th1 cells, macrophages, interferon (IFN) $-\gamma$, and dendritic cell IL- $12 .{ }^{54}$ IL-6 induces the proliferation, differentiation and activation of T-cells. ${ }^{55-57}$ IL-2 secreted by activated T-cells is necessary for the growth and differentiation of the T-cell lineage to become 'effector' T-cells. ${ }^{58-60}$ Interaction between IL-2 and its receptor stimulates the growth and development of T-cell immunological memory ${ }^{61-63}$ and facilitates the production of immunoglobulins by B-cells to induce the differentiation and proliferation of natural killer cells. ${ }^{64}$ The finding of elevations of both IL-4 and IL-6 indicates the chronic inflammation-mediated response of the retinal environment to HMGB-1.

Recent studies suggest a direct relationship between TLR-4 and apoptosis, showing that stimulation of TLR-4 promotes decay of epithelial cells via a Fas-associated death-domain protein-dependent pathway. ${ }^{65-68}$ In microglial cells, TLR-4associated but not TLR-2-associated apoptosis occurs through autocrine/paracrine IFN- $\beta$ production. ${ }^{69}$ An increase of TLR-4 promotes an association of elevated pressure to guide neuronal tissue-like photoreceptors or retina explants to apoptosis. Missing elevation of TLR- 4 together with an isolated elevation of TLR-2 after endogenous HMGB-1 exposure may indicate a pivotal role of TLR- 4 in retinae affected by elevated pressure. However, TLR-4-mediated apoptosis may be associated with the secondary release of cytokines, such as TNF- $\alpha$. In the present experimental setup, endogenous HMGB-1 does not activate TLR-4 signaling and does not promote a secondary release of TNF- $\alpha$ within retinal explants. Those findings promote recent findings indicating the independence of TLR-4 signaling in HMGB-1-affected tissue and related apoptosis in non-neuronal tissue. ${ }^{70}$

The present study further shows that regulation of HMGB-1 in retinal explants occurs under conditions of elevated pressure. The upregulation of RAGE suggests that elevated pressure switches the retinal environment into a pro-inflammatory one. The findings that elevated RAGE expression occurs in several major cells of the complex retinal cellular network rather than in photoreceptors (661W cells) alone. The comparable upregulation of RAGE together with a downregulation of TNF- $\alpha$ within retinal explants exposed to exogenous HMGB-1 promotes the link between HMGB-1 and RAGE within the retinal inflammatory milieu. The upregulation of pro-survival Bcl-2 suggests an overall transformation of pressure- and HMGB-1-exposed retinal cells into a pro-survival state. This pro-inflammatory response is not contradictory to the apoptosis in vulnerable retinal ganglion cells and photoreceptors because 
pro-inflammation is attributed to less vulnerable astrocytes and microglial cells, which did not show signs of apoptosis. Finally, the impact of exogenous HMGB-1 to the retinal environment promotes the theory of 'second-hit' strategies as a lasting response to elevated pressure-induced HMGB-1 release. Both elevated air pressure and rHMGB-1 promote switching of the retinal environment into a pro-inflammatory and a likely general pro-survival state, without excluding death of some subsets of neuronal cells.

In summary, our results support the thesis that photoreceptors may respond with degressive cascades when exposed to elevated pressure, although the release of HMGB- 1 and the pro-inflammatory response in $661 \mathrm{~W}$ cells may not indicate the sole mechanism for photoreceptor loss in glaucomatous eyes. Moreover, this is the first report describing the release of HMGB-1, the inflammatory response and association with apoptosis in a high-pressure model in vitro. Moreover, the present study revealed the distinct involvement of HMGB-1 in the regulation of cytokines and apoptosis. Future studies should evaluate the mechanisms of HGMB-1 in glaucoma and its possible role in other retinal pathologies.

\section{ACKNOWLEDGMENTS}

We thank M Wissing and M Langkamp-Flock for their skillful technical assistance and English Science Editing for native linguistic editing of the manuscript. This work was supported by an Innovative Medical Research (IMF) grant awarded by the School of Medicine, Westfalian-Wilhelms-University of Münster (I-Bö221307 to MRRB) and a German research foundation (DFG) grant (Th 386/20-1 to ST).

\section{DISCLOSURE/CONFLICT OF INTEREST}

The authors declare no conflict of interest.

1. The Advanced Glaucom Intervention Study (AGIS): 7. The relationship between control of intraocular pressure and visual field deterioration. The AGIS Investigators. Am J Ophthalmol 2000;130:429-440.

2. Kass MA, Heuer DK, Higginbotham EJ et al. The Ocular Hypertension Treatment Study: a randomized trial determines that topical ocular hypotensive medication delays or prevents the onset of primary open-angle glaucoma. Arch Ophthalmol 2002;120:701-713.

3. Whitmore AV, Libby RT, John SW. Glaucoma: thinking in new ways-a role for autonomous axonal self-destruction and other compartmentalised processes? Prog Retin Eye Res 2005;24:639-662.

4. Kwong JM, Vo N, Quan A et al. The dark phase intraocular pressure elevation and retinal ganglion cell degeneration in a rat model of experimental glaucoma. Exp Eye Res 2013;112:21-28.

5. Ueno M, Naumann GO. Uveal damage in secondary glaucoma. A morphometric study. Graefes Arch Clin Exp Ophthalmol 1989;227: 380-383.

6. Panda S, Jonas JB. Decreased photoreceptor count in human eyes with secondary angle-closure glaucoma. Invest Ophthalmol Vis Sci 1992;33: 2532-2536.

7. Velten IM, Korth M, Horn FK. The a-wave of the dark adapted electroretinogram in glaucomas: are photoreceptors affected? $\mathrm{Br} J$ Ophthalmol 2001;85:397-402.

8. Vincent A, Shetty R, Devi SA et al. Functional involvement of cone photoreceptors in advanced glaucoma: a multifocal electroretinogram study. Doc Ophthalmol 2010;121:21-27.

9. Nork TM, Ver Hoeve JN, Poulsen GL et al. Swelling and loss of photoreceptors in chronic human and experimental glaucomas. Arch Ophthalmol 2000;118:235-245.

10. Ortin-Martinez A, Salinas-Navarro M, Nadal-Nicolas FM et al. Laserinduced ocular hypertension in adult rats does not affect non-RGC neurons in the ganglion cell layer but results in protracted severe loss of cone-photoreceptors. Exp Eye Res 2015;132:17-33.

11. Limana F, Germani A, Zacheo A et al. Exogenous high-mobility group box 1 protein induces myocardial regeneration after infarction via enhanced cardiac C-kit+ cell proliferation and differentiation. Circ Res 2005;97:e73-e83.

12. Lotze MT, Tracey KJ. High-mobility group box 1 protein (HMGB1): nuclear weapon in the immune arsenal. Nat Rev Immunol 2005;5: 331-342.

13. Ulloa L, Messmer D. High-mobility group box 1 (HMGB1) protein: friend and foe. Cytokine Growth Factor Rev 2006;17:189-201.

14. Kim JB, Sig Choi J, Yu YM et al. HMGB1, a novel cytokine-like mediator linking acute neuronal death and delayed neuroinflammation in the postischemic brain. J Neurosci 2006;26:6413-6421.

15. Liu K, Mori S, Takahashi HK et al. Anti-high mobility group box 1 monoclonal antibody ameliorates brain infarction induced by transient ischemia in rats. FASEB J 2007;21:3904-3916.

16. Huang $W$, Tang $Y$, Li L. HMGB1, a potent proinflammatory cytokine in sepsis. Cytokine 2010;51:119-126.

17. Pedrazzi M, Raiteri L, Bonanno G et al. Stimulation of excitatory amino acid release from adult mouse brain glia subcellular particles by high mobility group box 1 protein. J Neurochem 2006;99:827-838.

18. Klune JR, Dhupar R, Cardinal J et al. HMGB1: endogenous danger signaling. Mol Med 2008;14:476-484.

19. Watanabe T, Keino H, Sato $Y$ et al. High mobility group box protein-1 in experimental autoimmune uveoretinitis. Invest Ophthalmol Vis Sci 2009;50:2283-2290.

20. Mohammad G, Siddiquei MM, Othman A et al. High-mobility group box-1 protein activates inflammatory signaling pathway components and disrupts retinal vascular-barrier in the diabetic retina. Exp Eye Res 2013;107:101-109.

21. Schallenberg M, Prokosch V, Thanos S. Regulation of retinal proteome by topical antiglaucomatous eye drops in an inherited glaucoma rat model. PLoS One 2012;7:e33593.

22. Krishnamoorthy RR, Clark AF, Daudt D et al. A forensic path to RGC-5 cell line identification: lessons learned. Invest Ophthalmol Vis Sci 2013;54:5712-5719.

23. Shi $\mathrm{H}$, Williams JA, Guo $L$ et al. Exposure to the complement C5b-9 complex sensitizes $661 \mathrm{~W}$ photoreceptor cells to both apoptosis and necroptosis. Apoptosis 2015;20:433-443.

24. Murakami $\mathrm{Y}$, Matsumoto $\mathrm{H}$, Roh $\mathrm{M}$ et al. Programmed necrosis, not apoptosis, is a key mediator of cell loss and DAMP-mediated inflammation in dsRNA-induced retinal degeneration. Cell Death Differ 2014;21:270-277.

25. Nativel B, Marimoutou M, Thon-Hon VG et al. Soluble HMGB1 is a novel adipokine stimulating IL-6 secretion through RAGE receptor in SW872 preadipocyte cell line: contribution to chronic inflammation in fat tissue. PLoS One 2013;8:e76039.

26. Wang YE, Park A, Lake $M$ et al. Ubiquitin-regulated nuclear-cytoplasmic trafficking of the Nipah virus matrix protein is important for viral budding. PLoS Pathog 2010;6:e1001186.

27. Klune JR, Billiar TR, Tsung A. HMGB1 preconditioning: therapeutic application for a danger signal? J Leukoc Biol 2008;83:558-563.

28. Park JS, Svetkauskaite D, He Q et al. Involvement of toll-like receptors 2 and 4 in cellular activation by high mobility group box 1 protein. J Biol Chem 2004;279:7370-7377.

29. Kokkola R, Andersson A, Mullins $G$ et al. RAGE is the major receptor for the proinflammatory activity of HMGB1 in rodent macrophages. Scand J Immunol 2005;61:1-9.

30. Nogueira-Machado JA, de Oliveira Volpe CM. HMGB-1 as a target for inflammation controlling. Recent Pat Endocr Metab Immune Drug Discov 2012;6:201-209.

31. Abeyama K, Eng W, Jester JV et al. A role for NF-kappaB-dependent gene transactivation in sunburn. J Clin Invest 2000;105:1751-1759.

32. Schmidt AM, Yan SD, Yan SF et al. The multiligand receptor RAGE as a progression factor amplifying immune and inflammatory responses. J Clin Invest 2001;108:949-955.

33. Sunahori K, Yamamura M, Yamana J et al. Increased expression of receptor for advanced glycation end products by synovial tissue macrophages in rheumatoid arthritis. Arthritis Rheum 2006;54: 97-104.

34. Okamoto $H$, Katagiri $Y$, Kiire $A$ et al. Serum amyloid $A$ activates nuclear factor-kappaB in rheumatoid synovial fibroblasts through binding to 
receptor of advanced glycation end-products. J Rheumatol 2008;35: 752-756.

35. Taniguchi N, Kawahara K, Yone $\mathrm{K}$ et al. High mobility group box chromosomal protein 1 plays a role in the pathogenesis of rheumatoid arthritis as a novel cytokine. Arthritis Rheum 2003;48:971-981.

36. Oyama J, Blais Jr C, Liu X et al. Reduced myocardial ischemiareperfusion injury in toll-like receptor 4-deficient mice. Circulation 2004;109:784-789.

37. Wu H, Chen G, Wyburn KR et al. TLR4 activation mediates kidney ischemia/reperfusion injury. J Clin Invest 2007;117:2847-2859.

38. Takeda K, Akira S. Toll-like receptors. Curr Protoc Immunol 2007; Chapter 14:12.

39. Tsung A, Klune JR, Zhang X et al. HMGB1 release induced by liver ischemia involves Toll-like receptor 4 dependent reactive oxygen species production and calcium-mediated signaling. J Exp Med 2007;204:2913-2923.

40. Zanotti G, Casiraghi M, Abano JB et al. Novel critical role of Toll-like receptor 4 in lung ischemia-reperfusion injury and edema. Am J Physiol Lung Cell Mol Physiol 2009;297:L52-L63.

41. Kawai T, Akira S. The role of pattern-recognition receptors in innate immunity: update on Toll-like receptors. Nat Immunol 2010;11: 373-384.

42. Yang $\mathrm{H}$, Hreggvidsdottir $\mathrm{HS}$, Palmblad $\mathrm{K}$ et al. A critical cysteine is required for HMGB1 binding to Toll-like receptor 4 and activation of macrophage cytokine release. Proc Natl Acad Sci USA 2010;107: 11942-11947.

43. Scaffidi P, Misteli T, Bianchi ME. Release of chromatin protein HMGB1 by necrotic cells triggers inflammation. Nature 2002;418: 191-195.

44. Rovere-Querini $P$, Capobianco $A$, Scaffidi $P$ et al. HMGB1 is an endogenous immune adjuvant released by necrotic cells. EMBO Rep 2004;5:825-830.

45. Bell CW, Jiang W, Reich 3rd CF et al. The extracellular release of HMGB1 during apoptotic cell death. Am J Physiol Cell Physiol 2006;291:C1318-C1325.

46. Boehm MR, Oellers $P$, Thanos S. Inflammation and immunology of the vitreoretinal compartment. Inflamm Allergy Drug Targets 2011;10: 283-309.

47. Wahl SM, McCartney-Francis N, Mergenhagen SE. Inflammatory and immunomodulatory roles of TGF-beta. Immunol Today 1989;10: 258-261.

48. Ma W, Lee SE, Guo J et al. RAGE ligand upregulation of VEGF secretion in ARPE-19 cells. Invest Ophthalmol Vis Sci 2007;48:1355-1361.

49. Plata-Salaman CR. Immunoregulators in the nervous system. Neurosci Biobehav Rev 1991;15:185-215.

50. Beutler B, Cerami A. The biology of cachectin/TNF-a primary mediator of the host response. Annu Rev Immunol 1989;7:625-655.

51. Benson MT, Shepherd L, Rees RC et al. Production of interleukin- 6 by human retinal pigment epithelium in vitro and its regulation by other cytokines. Curr Eye Res 1992;11:173-179.
52. Jaffe GJ, Van Le L, Valea $F$ et al. Expression of interleukin-1 alpha, interleukin-1 beta, and an interleukin-1 receptor antagonist in human retinal pigment epithelial cells. Exp Eye Res 1992;55:325-335.

53. Zhou JG, Zheng M. Role of HMGB1 in rheumatic diseases. Zhejiang Da Xue Xue Bao Yi Xue Ban 2007;36:412-416.

54. Kumar V, Abbas AK, Fausto $\mathrm{N}$ et al. Robbins and Cotran Pathologic Basis of Disease. Saunders: Philadelphia, PA, USA, 2010.

55. Holsti MA, McArthur J, Allison JP et al. Role of IL-6, IL-1, and CD28 signaling in responses of mouse CD4+ T cells to immobilized anti-TCR monoclonal antibody. J Immunol 1994;152:1618-1628.

56. Gajewski TF, Renauld JC, Van Pel A et al. Costimulation with B7-1, IL-6, and IL-12 is sufficient for primary generation of murine antitumor cytolytic T lymphocytes in vitro. J Immunol 1995;154:5637-5648.

57. Mima T, Nishimoto N. Clinical value of blocking IL-6 receptor. Curr Opin Rheumatol 2009;21:224-230.

58. Cantrell DA, Smith KA. The interleukin-2 T-cell system: a new cell growth model. Science 1984;224:1312-1316.

59. Smith KA. Interleukin 2. Annu Rev Immunol 1984;2:319-333.

60. Garman RD, Jacobs KA, Clark SC et al. B-cell-stimulatory factor 2 (beta 2 interferon) functions as a second signal for interleukin 2 production by mature murine T cells. Proc Natl Acad Sci USA 1987;84:7629-7633.

61. Beadling $C$, Johnson KW, Smith KA. Isolation of interleukin 2-induced immediate-early genes. Proc Natl Acad Sci USA 1993;90:2719-2723.

62. Sakaguchi S, Sakaguchi N, Asano M et al. Immunologic self-tolerance maintained by activated T cells expressing IL-2 receptor alpha-chains (CD25). Breakdown of a single mechanism of self-tolerance causes various autoimmune diseases. J Immunol 1995;155:1151-1164.

63. Beadling C, Smith KA. DNA array analysis of interleukin-2-regulated immediate/early genes. Med Immunol 2002;1:2.

64. Waldmann TA, Tagaya Y. The multifaceted regulation of interleukin-15 expression and the role of this cytokine in NK cell differentiation and host response to intracellular pathogens. Annu Rev Immunol 1999;17:19-49.

65. Aliprantis AO, Yang RB, Weiss DS et al. The apoptotic signaling pathway activated by Toll-like receptor-2. EMBO J 2000;19:3325-3336.

66. Haase $\mathrm{R}$, Kirschning $\mathrm{CJ}$, Sing $\mathrm{A}$ et al. A dominant role of Toll-like receptor 4 in the signaling of apoptosis in bacteria-faced macrophages. J Immunol 2003;171:4294-4303.

67. Fan W, Ha T, Li Y et al. Overexpression of TLR2 and TLR4 susceptibility to serum deprivation-induced apoptosis in $\mathrm{CHO}$ cells. Biochem Biophys Res Commun 2005;337:840-848.

68. Maratheftis $\mathrm{Cl}$, Andreakos $\mathrm{E}$, Moutsopoulos $\mathrm{HM}$ et al. Toll-like receptor 4 is up-regulated in hematopoietic progenitor cells and contributes to increased apoptosis in myelodysplastic syndromes. Clin Cancer Res 2007;13:1154-1160.

69. Jung DY, Lee $\mathrm{H}$, Jung BY et al. TLR4, but not TLR2, signals autoregulatory apoptosis of cultured microglia: a critical role of IFNbeta as a decision maker. J Immunol 2005;174:6467-6476.

70. Dehbi M, Uzzaman T, Baturcam E et al. Toll-like receptor 4 and highmobility group box 1 are critical mediators of tissue injury and survival in a mouse model for heatstroke. PLoS One 2012;7:e44100. 